\title{
Aerosol- and greenhouse gas-induced changes in summer rainfall and circulation in the Australasian region: a study using single-forcing climate simulations
}

\author{
L. D. Rotstayn ${ }^{1}$, S. J. Jeffrey ${ }^{2}$, M. A. Collier ${ }^{1}$, S. M. Dravitzki ${ }^{1}$, A. C. Hirst ${ }^{1}$, J. I. Syktus ${ }^{2}$, and K. K. Wong ${ }^{2}$ \\ ${ }^{1}$ Centre for Australian Weather and Climate Research, CSIRO Marine and Atmospheric Research, Aspendale, Vic, Australia \\ ${ }^{2}$ Queensland Climate Change Centre of Excellence, Dutton Park, Qld, Australia
}

Correspondence to: L. D. Rotstayn (leon.rotstayn@csiro.au)

Received: 27 January 2012 - Published in Atmos. Chem. Phys. Discuss.: 15 February 2012

Revised: 17 May 2012 - Accepted: 1 July 2012 - Published: 23 July 2012

\begin{abstract}
We use a coupled atmosphere-ocean global climate model (CSIRO-Mk3.6) to investigate the drivers of trends in summer rainfall and circulation in the vicinity of northern Australia. As part of the Coupled Model Intercomparison Project Phase 5 (CMIP5), we perform a 10-member 21st century ensemble driven by Representative Concentration Pathway 4.5 (RCP4.5). To investigate the roles of different forcing agents, we also perform multiple 10-member ensembles of historical climate change, which are analysed for the period 1951-2010. The historical runs include ensembles driven by "all forcings" (HIST), all forcings except anthropogenic aerosols (NO_AA) and forcing only from longlived greenhouse gases (GHGAS). Anthropogenic aerosolinduced effects in a warming climate are calculated from the difference of HIST minus NO_AA.

CSIRO-Mk3.6 simulates a strong summer rainfall decrease over north-western Australia (NWA) in RCP4.5, whereas simulated trends in HIST are weakly positive (but insignificant) during 1951-2010. The weak rainfall trends in HIST are due to compensating effects of different forcing agents: there is a significant decrease in GHGAS, offset by an aerosol-induced increase.

Observations show a significant increase of summer rainfall over NWA during the last few decades. The large magnitude of the observed NWA rainfall trend is not captured by 440 unforced $60-y r$ trends calculated from a $500-y r$ preindustrial control run, even though the model's decadal variability appears to be realistic. This suggests that the observed trend includes a forced component, despite the fact that the model does not simulate the magnitude of the observed rainfall increase in response to "all forcings" (HIST).
\end{abstract}

We investigate the mechanism of simulated and observed NWA rainfall changes by exploring changes in circulation over the Indo-Pacific region. The key circulation feature associated with the rainfall increase in reanalyses is a lowertropospheric cyclonic circulation trend off the coast of NWA, which enhances the monsoonal flow. The model shows an aerosol-induced cyclonic circulation trend off the coast of NWA in HIST minus NO_AA, whereas GHGAS shows an anticyclonic circulation trend. This explains why the aerosolinduced effect is an increase of rainfall over NWA, and the greenhouse gas-induced effect is of opposite sign.

Possible explanations for the cyclonic (anticyclonic) circulation trend in HIST minus NO_AA (GHGAS) involve changes in the Walker circulation or the local Hadley circulation. In either case, a plausible atmospheric mechanism is that the circulation anomaly is a Rossby wave response to convective heating anomalies south of the Equator. We also discuss the possible role of air-sea interactions, e.g. an increase (decrease) of sea-surface temperatures off the coast of NWA in HIST minus NO_AA (GHGAS). Further research is needed to better understand the mechanisms and the extent to which these are model-dependent.

In summary, our results suggest that anthropogenic aerosols may have "masked" greenhouse gas-induced changes in rainfall over NWA and in circulation over the wider Indo-Pacific region. Due to the opposing effects of greenhouse gases and anthropogenic aerosols, future trends may be very different from trends observed over the last few decades. 


\section{Introduction}

Aerosols are known to affect climate via direct and indirect effects on radiation. These effects are thought to be large but very uncertain, especially the indirect effects, whereby aerosols modify the albedo and lifetime of clouds. According to Forster et al. (2007), the best estimate for the globalmean net anthropogenic aerosol forcing (including direct effects and the cloud-albedo effect) is $-1.2 \mathrm{~W} \mathrm{~m}^{-2}$, which is almost half the magnitude of the positive radiative forcing of $2.6 \mathrm{~W} \mathrm{~m}^{-2}$ from long-lived greenhouse gases (GHGs). Thus, aerosols are understood to substantially mask the effects of GHG-induced warming on global-mean temperature. Because concentrations of anthropogenic aerosols are projected to decrease during the next few decades, the associated "unmasking" is likely to exacerbate the increase of global-mean temperature (Kloster et al., 2010). Further, the hydrological sensitivity (defined as the change in global-mean precipitation per unit change in temperature) is thought to be higher for aerosols than for GHG-induced changes (Liepert et al., 2004; Kloster et al., 2010). This can be explained by separating the precipitation change into a "fast" response to the atmospheric heating caused by the forcing agent, and a "slow" response, which scales with the change in global-mean temperature (Ming et al., 2010; Andrews et al., 2010; Ming and Ramaswamy, 2011).

In addition to these globally averaged effects, there are large climatic effects due to strong spatial variations in the distribution of aerosols. This spatial inhomogeneity can cause large changes in atmospheric circulation and rainfall, especially in the tropics, where the circulation is known to be sensitive to horizontal temperature gradients (Rotstayn and Lohmann, 2002). This can be referred to as the "dynamic" effect of aerosol forcing (Ming and Ramaswamy, 2011). To first order, this dynamic effect can be described as a southward shift of the intertropical convergence zone (Rotstayn et al., 2000; Williams et al., 2001), or a weakening of the Hadley circulation in the Northern Hemisphere and a strengthening in the Southern Hemisphere (Ming and Ramaswamy, 2011). This can be explained in terms of the interhemispheric asymmetry in aerosol forcing, or the resultant change in the latitude of the maximum sea-surface temperature (SST).

Recent research has also identified an important "thermodynamic" effect of anthropogenic aerosols on circulation and rainfall (Ming and Ramaswamy, 2011; Bollasina et al., 2011). This argument suggests that, regardless of the spatial pattern of forcing, the cooling effects of aerosols counter the GHG-induced weakening of tropical circulation. The latter is driven by the difference between rapidly increasing lower-tropospheric water vapour in a warming climate, and the precipitation rate, which increases more slowly (Knutson and Manabe, 1995; Held and Soden, 2006; Vecchi and Soden, 2007). The GHG-induced weakening is thought to act more strongly on the zonally asymmetric (Walker) cir- culation than on the zonally symmetric (Hadley) circulation (Vecchi and Soden, 2007). By implication, the same would apply to the thermodynamic effect of anthropogenic aerosols. Vecchi et al. (2006) analysed observations of sea-level pressure and found that the Pacific Walker circulation has indeed weakened since the mid-19th century. However, some studies based on satellite retrievals (Chen et al., 2002; Wentz et al., 2007) suggest that tropical circulation has strengthened in recent decades, reinforcing the point that these are unresolved research issues.

Early modelling of the response to aerosol forcing used atmospheric global climate models (GCMs) coupled to very simple "slab" ocean models, in which oceanic heat transports are prescribed (e.g. Rotstayn et al., 2000; Williams et al., 2001; Roberts and Jones, 2004; Kristjánsson et al., 2005). However, these models cannot capture the effects of changes in ocean dynamics, or the transient nature of climate change induced by aerosols (or any other forcing agent). For this reason, there has been an increasing trend in recent years to use fully coupled atmosphere-ocean GCMs (AOGCMs) to investigate these effects, even though they are much more complex and computationally expensive than atmospheric GCMs. For example, there have been several studies with AOGCMs of the effects of anthropogenic aerosols on the South Asian monsoon (Ramanathan et al., 2005; Meehl et al., 2008; Bollasina et al., 2011) and on rainfall in the Sahel (Kawase et al., 2010; Ackerley et al., 2011). Arblaster and Meehl (2006) used a similar approach to determine the contributions of different forcing agents to changes in the Southern Annular Mode. Using a low-resolution AOGCM, Rotstayn et al. (2007) investigated the effects of aerosol direct and indirect forcing on Australian rainfall. With a different focus, Roeckner et al. (2006) compared 21st century projections with two different assumptions about future emissions of carbonaceous aerosols, and found a marked sensitivity of the climate response over central Africa. To be effective, this approach generally requires substantial ensembles of simulations in which the effects of different forcing agents are treated individually, which further increases the computational expense.

Phase five of the Coupled Model Intercomparison Project (CMIP5) is currently in progress, and will continue through 2013. The CMIP5 experimental design (Taylor et al., 2009, 2012) does include provision for historical runs driven by individual forcing agents, but these are designated as "tier 2", the lowest priority of the three sets of experiments (Taylor et al., 2009, their Table 7). However, the importance of these simulations has increasingly been recognised, and efforts are underway to ensure that a substantial number of groups contribute such simulations to the CMIP5 data archive (e.g. Boucher et al., 2011).

Over the last few decades, there has been a significant rainfall increase over north-western Australia (NWA). Figure 1 shows observed December to March (DJFM) rainfall trends from the Australian Water Availability Project (AWAP; Jones 


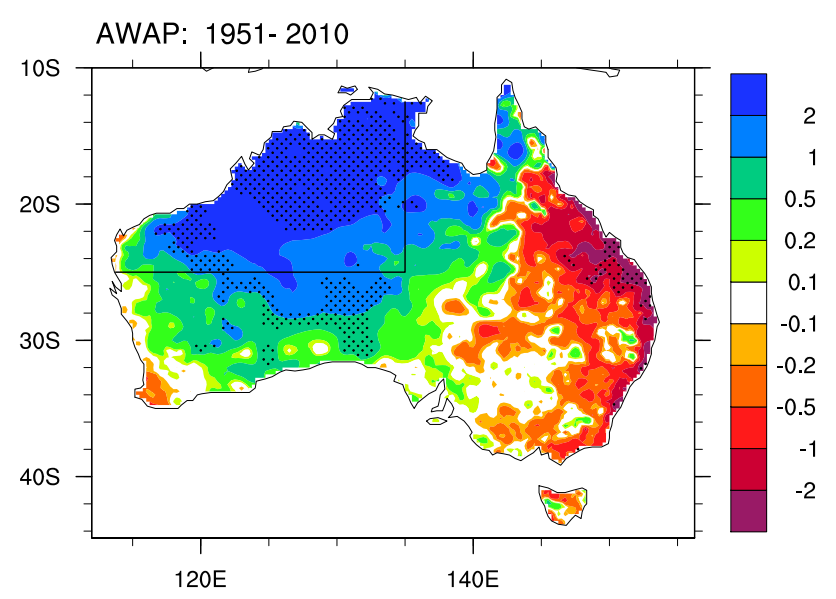

Fig. 1. Observed DJFM rainfall trends from AWAP $\left(\mathrm{mm} \mathrm{day}^{-1}\right.$ century $\left.^{-1}\right)$ for 1951-2010. Stippled trends are significant at $5 \%$ based on a t-test, after adjusting for the serial correlation. The area enclosed by the black lines (land only) denotes the region referred to as north-western Australia in some of the following analysis.

et al., 2009) for December 1950 to March 2010. (Hereafter, we refer to this period as 1951-2010 when showing results for DJFM.) Although there is some evidence of a significant drying trend over limited parts of eastern Australia, the dominant feature is increasing rainfall over the north-west and centre of the continent. Over this region, most of the rainfall occurs in summer, and the cause of the trend may be policyrelevant for decisions regarding agriculture, mining infrastructure and regional communities.

A few authors have sought explanations for this trend, with no clear consensus emerging as yet. The first attempt was by Wardle and Smith (2004), who simulated a rainfall increase over northern Australia by decreasing surface albedo over the continent, though the prescribed decreases were much larger than could be justified based on current knowledge. Recognising the idealised nature of their experiment, the authors left the cause of the rainfall increase as an open question.

Rotstayn et al. (2007) used a low-resolution (spectral R21) version of the CSIRO GCM ("Mk3A") to perform ensembles of coupled ocean-atmosphere simulations for the period 1871-2000, with and without changes in anthropogenic aerosols. They found that inclusion of anthropogenic aerosol forcing gave a rainfall response similar to the observed increase over NWA. They attributed this to a change in the meridional temperature gradient induced by aerosols from the Asian region. However, they also expressed a number of reservations about their results, including simplified and uncertain treatments of aerosol processes, a lack of agreement between modelled and observed rainfall trends in other parts of Australia, and a poor simulation of variability associated with the El Niño-Southern Oscillation (ENSO) in their lowresolution model.
The issue of ENSO-related variability in CSIRO Mk3A was taken up in more detail by Shi et al. (2008). They pointed out that the low-resolution model suffers from an equatorial Pacific cold-tongue bias, with the effect that the SST anomalies associated with ENSO extend too far west into the eastern Indian Ocean. Consequently, in austral summer ENSO-related rainfall variability over Australia was also shifted westward, from north-eastern Australia towards NWA. The cold-tongue bias is a long-standing problem in coupled AOGCMs (Latif et al., 2001), which suggests that other models will also be affected to varying degrees.

Cai et al. (2011) revisited the question using 24 models from CMIP3. They found that only nine models produce a statistically significant increasing rainfall trend over NWA, and all were much weaker than the observed trend for 19502008. They then grouped the models according to whether they treated both direct and indirect anthropogenic aerosol effects, or direct effects only, and found little difference between the two groups. They concluded that increasing anthropogenic aerosols in the multi-model ensemble play a negligible role in generating the observed rainfall increase over NWA. They also found that projected 21 st century rainfall changes over NWA were highly variable among the models, with a mixture of both positive and negative changes. Note that this implies that the response of NWA rainfall to increasing long-lived GHGs is highly variable among the CMIP3 models, so it is also likely that the response to anthropogenic aerosol forcing (which is much more uncertain and spatially inhomogeneous) will be highly variable. Aside from the very simplified aerosol treatments in many CMIP3 models, this may explain why Cai et al. (2011) were unable to detect a clear anthropogenic aerosol signal. However, the lack of individual-forcing simulations in the CMIP3 data set makes it difficult to draw firm conclusions.

Several other studies have investigated aspects of the NWA rainfall increase. Zhang (2010) found that the observed significant increase in NWA summer rainfall corresponds to earlier onset and duration of the monsoon, rather than an increase in intensity of rainfall events. Luffman et al. (2010) evaluated the response of an atmospheric GCM forced by observed changes in SST in the Indian and Pacific Oceans (both separately and together). They found that none of the experiments simulated an east-west pattern of rainfall trend over Australia that resembled the observed trends. They suggested that while the drying trend in the east may be partially explained by changes in the tropical Indian and Pacific SST, increasing rainfall in the north-west must be related to other factors. Berry et al. (2011) examined the synoptic-scale processes associated with rainfall events in NWA. They found that prior to rain falling in the interior of NWA, there is a shift in the origins of low-level air parcels, such that air is advected from the tropical maritime regions, rather than from over the continent. They also suggested that the observed increase in rainfall may be primarily linked to changes in synoptic weather systems, rather than changes in the state of the 
ocean. Recently, Lin and Li (2012) used reanalysis data to show that an increasing trend in atmospheric ascent induced by a warming SST trend in the tropical Atlantic may partially explain the observed rainfall trend in NWA. Their suggested mechanism involves a Rossby wave train that travels eastward, embedded in the westerly jet waveguide of the Southern Hemisphere.

Another relevant study was by Zhang and Zhang (2010), who pointed out a positive correlation (on inter-annual time scales) between the Australian monsoon and the East Asian winter monsoon. Although their focus was not on longterm rainfall trends, they suggested that variations in crossequatorial flow and the upward branch of the Hadley circulation create an important link between the two monsoons.

Here we use individual-forcing experiments with a coupled AOGCM to investigate the cause of recent Australian summer rainfall trends, and in particular, whether there is a link to anthropogenic forcing. The individual-forcing simulations used in this study comprise part of a CMIP5 submission with the CSIRO Mark 3.6 (CSIRO-Mk3.6) GCM. CSIRO-Mk3.6 simulates a significant decrease of rainfall over NWA during 1951-2010 in response to forcing from long-lived GHGs, which is offset by forcing from anthropogenic aerosols. The simulated response to "all forcings" is small and not significant, mainly due to cancellation of the effects of long-lived GHGs and aerosols. We show that the observed increase of NWA rainfall is associated with a lower-tropospheric cyclonic circulation trend off the coast of NWA in reanalyses, which strengthens the monsoonal flow. The aerosol-induced response in the model shows a similar cyclonic circulation trend, whereas the GHG-induced circulation response is of opposite sign. We then discuss possible mechanisms that drive the opposing simulated effects of GHGs and aerosols, in terms of changes in the Walker circulation or the local Hadley circulation.

\section{Model and simulations}

\subsection{Overview of model}

The CSIRO Mark 3.6 (CSIRO-Mk3.6) GCM was developed from the earlier Mk3.5 version, which was described in detail by Gordon et al. (2002, 2010). It is a coupled atmosphere-ocean model with dynamic sea ice. It also has a soil-canopy scheme with prescribed vegetation properties. The ocean, sea-ice and soil-canopy models are unchanged between $\mathrm{Mk} 3.5$ and $\mathrm{Mk} 3.6$.

The main differences between Mk3.5 and Mk3.6 are the inclusion of an interactive aerosol treatment and an updated radiation scheme in Mk3.6. The aerosol scheme treats sulfate, carbonaceous aerosol, mineral dust and sea salt. The radiation scheme treats the direct effects of all these aerosol species on shortwave radiation and the effects of dust on longwave radiation. The indirect effects of sulfate, carbona- ceous aerosol and sea salt on liquid-water clouds are also included, via an empirical parameterization of cloud droplet concentration as a function of aerosol number concentration. The Supplement contains further details about the model, with a primary focus on the aerosol treatments and their interactions with radiation and clouds.

\subsection{Prescribed data sets}

Our simulations are based on the CMIP5 experimental design (Taylor et al., 2009, 2012); see http://cmip-pcmdi. 1lnl.gov/cmip5/ for further information about CMIP5 forcing data. Anthropogenic forcing agents in our runs are long-lived GHGs, ozone and aerosols. (Changes in land use are not included.) We prescribed CMIP5-recommended, annual-mean concentrations of long-lived GHGs (carbon dioxide, methane, nitrous oxide and chlorofluorocarbons), and monthly mean, spatially varying ozone concentrations. Ozone concentrations are based on the AC\&C/SPARC ozone database (Cionni et al., 2011); they are three dimensional in the troposphere, and zonally averaged in the stratosphere. Emissions of anthropogenic aerosols and aerosol precursors also follow CMIP5 recommendations (Lamarque et al., 2010), with modifications as described in the Supplement. In addition to direct effects and indirect aerosol effects on liquid-water clouds, the model also includes a simple treatment of the effect of black carbon on snow albedo (Hansen and Nazarenko, 2004). The anthropogenic-forcing data sets are prescribed for both the historical period and the four Representative Concentration Pathways (RCPs); see Moss et al. (2010) for an overview of the RCPs. We also included the historical time series of annual-mean total solar irradiance recommended for CMIP5; this includes estimates of both the 11-yr solar cycle and changes in background irradiance (Lean, 2000; Wang et al., 2005).

CMIP5 does not specifically include a prescribed data set for volcanic forcing. We prescribed zonally averaged distributions of stratospheric sulfate based on Sato et al. (1993) (http://data.giss.nasa.gov/modelforce/strataer/); a recent update, which extended the data set beyond 1999, was not available at the time we commenced the simulations, so we set volcanic forcing to zero from 2000 onwards. Stratospheric sulfate is distinct from the (time-invariant) source of sulfur from continuously erupting volcanoes in the model's tropospheric sulfur cycle; the latter is described in the Supplement.

\subsection{Aerosol forcing}

Since our main focus in this paper is to compare the effects of anthropogenic aerosols and GHGs, in this section we discuss the magnitude and spatial pattern of aerosol forcing. Globalmean aerosol burdens and optical depths are discussed in the Supplement; the main conclusion from that analysis is that the global-mean mid-visible anthropogenic aerosol optical depth in CSIRO-Mk3.6 is larger than the average of earlier 
models considered by Schulz et al. (2006), though it is not outside the range of these models.

The CMIP5 experimental design (Taylor et al., 2009) includes simulations designed to calculate an estimate of the radiative forcing due to anthropogenic aerosols. The method is based on two 30-yr atmospheric runs with prescribed SSTs and sea-ice taken as a long-term average from the preindustrial control run. One run uses 1850 aerosol emissions, whereas the other uses emissions for the year 2000. The difference in net top-of-atmosphere (TOA) radiation between the two runs gives an estimate of aerosol forcing, sometimes referred to as a "radiative flux perturbation" (RFP; Lohmann et al., 2010), or "adjusted troposphere and stratosphere forcing" (Shine et al., 2003). The RFP method is used because, once indirect aerosol effects other than the cloud-albedo effect are considered, it is not feasible to calculate an instantaneous forcing. Several studies have suggested that the RFP provides a satisfactory alternative to instantaneous forcing (Rotstayn and Penner, 2001; Hansen et al., 2002; Lohmann et al., 2010). In CSIRO-Mk3.6, the net (TOA) anthropogenic aerosol RFP from 1850 to 2000 is $-1.41 \pm 0.09 \mathrm{~W} \mathrm{~m}^{-2}$; the uncertainty range is a $95 \%$ confidence interval based on a two-sample t-test (Zar, 1996, chapter 8), assuming that the 30 annual-mean values from each run can be treated as independent. This represents the sum of direct and (first and second) indirect effects, plus the effect of black carbon on snow albedo. This result is a little larger in magnitude than the best estimate of $-1.2 \mathrm{~W} \mathrm{~m}^{-2}$ from Forster et al. (2007), though it is well within the large uncertainty range.

The total aerosol RFP at TOA is shown in Fig. 2. Despite the noise, which is an intrinsic feature of the RFP method, several features stand out. Possibly of relevance to the present study is that South and East Asia and the Indonesian region feature prominently, consistent with large emissions from these areas. Substantial forcings in regions of persistent low cloud cover, such as the eastern subtropics of the Pacific and Atlantic Ocean basins, are suggestive of indirect aerosol effects. The breakdown of aerosol forcing into direct and indirect effects is discussed in the Supplement.

\subsection{Transient simulations}

As well as most of the "core" and "tier 1" CMIP5 experiments, we performed a substantial set of 10-member individual-forcing historical ensembles (Experiments 7.2 and 7.3 in Taylor et al., 2009). These are designed to explore the effects of changes in GHGs, aerosols, ozone and natural (solar and volcanic) forcing. Here, we focus on the following 10-member ensembles:

- HIST: standard historical run with "all forcings", namely, long-lived GHGs, ozone, anthropogenic aerosols, and natural forcing.

- NO_AA: same as HIST, but with anthropogenic and biomass-burning aerosol emissions fixed at 1850 lev-

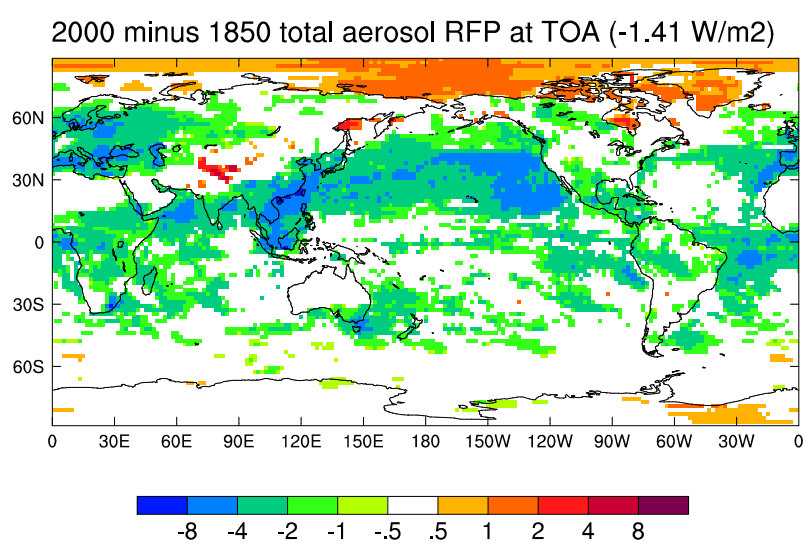

Fig. 2. Anthropogenic aerosol forcing (the difference between 2000 and 1850) in $\mathrm{W} \mathrm{m}^{-2}$, calculated as the total aerosol radiative flux perturbation at TOA. Only values significant at $5 \%$ are plotted, based on a two-sample t-test.

els. (We hereafter refer to these emissions collectively as "anthropogenic".)

- GHGAS: same as HIST, but forced only by changes in long-lived GHGs.

- RCP4.5: projection for 2006 to 2100 based on Representative Concentration Pathway 4.5, in which total radiative forcing is stabilized before 2100 at roughly $4.5 \mathrm{~W} \mathrm{~m}^{-2}$ (Clarke et al., 2007).

Each historical run was initialized in January, 1850 from states taken from years 80 to 200 of a $500-\mathrm{yr}$ preindustrial control run (piControl), at intervals of 10 to $17 \mathrm{yr}$. Each RCP4.5 run was initialized in January 2006 from the end of a run from the HIST ensemble. In principle, the CMIP5 historical period ends in 2005, but we extended all the historical runs from 2006 to 2012 by following the assumptions in RCP4.5. (Thus, the HIST ensemble is identical to RCP4.5 for 2006-2012). In the following analysis, we will calculate 60 -yr trends from the historical runs (1951-2010) and 90-yr trends from RCP4.5 (2011-2100).

An addition to the above simulations (which are "core" for the purpose of this study) we will also show some results from the following additional ensembles:

- NAT: same as HIST, but forced only by changes in volcanic and solar forcing.

- NO_OZ: same as HIST, but with ozone concentrations fixed at 1949 levels from 1950 onwards.

We use the difference of HIST minus NO_AA to diagnose the aerosol-induced effect. There is evidence from earlier studies with slab ocean models that the response is non-linear, suggesting that HIST minus NO_AA is not identical to an experiment forced only by anthropogenic aerosols (Feichter et al., 


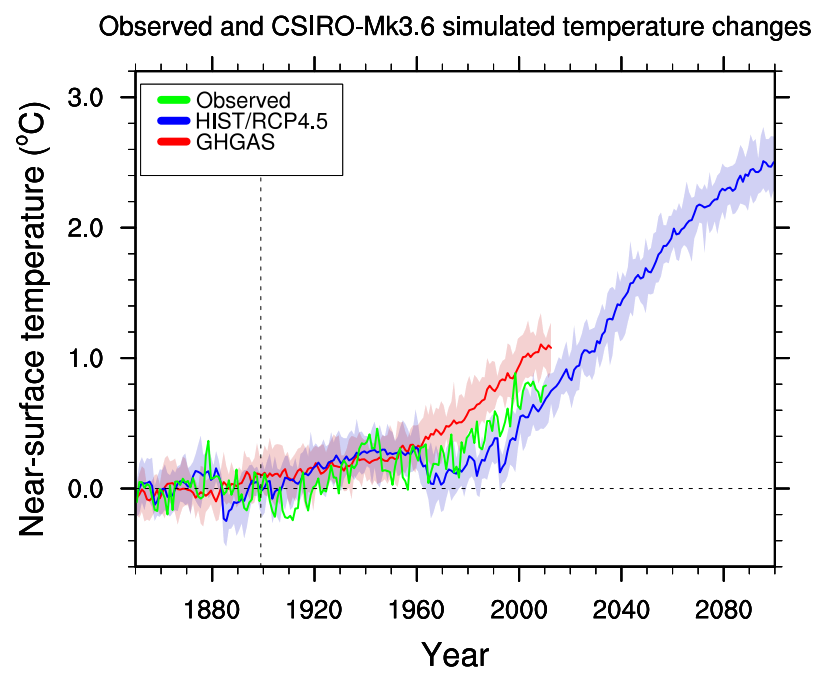

Fig. 3. Anomalies of annual, global-mean near-surface temperature from observations and the model (comprising SST over oceans, and near-surface air temperature over land). Solid lines show the ensemble mean, and shading shows the range of individual runs within each ensemble. Observations and the model both use their own 1850-1899 mean in the calculation of anomalies.

2004; Ming and Ramaswamy, 2009). However, aerosols in the real world act against a background of GHG-induced warming, so the approach of using HIST minus NO_AA may be more realistic. Similarly, the effects of changes in ozone are diagnosed from the difference of a pair of experiments (HIST minus NO_OZ).

Figure 3 shows anomalies of annual, global-mean nearsurface temperature $T_{\mathrm{S}}$ from the model and observations from HadCRUT3 (Brohan et al., 2006). Prior to about 1980, observed global-mean $T_{\mathrm{S}}$ is mostly within the range of runs in the HIST ensemble, except for a period in the early 20th century. The observed $T_{\mathrm{s}}$ curve in Fig. 3 does not show the observational uncertainties, which are larger than $\pm 0.2^{\circ} \mathrm{C}$ prior to 1940 (Brohan et al., 2006). HIST somewhat underestimates the observed warming towards the end of the 20th century. In contrast, the GHGAS ensemble overestimates the increase in $T_{\mathrm{s}}$. NO_AA (not shown) simulates slightly more warming than GHGAS, mainly due to changes in solar irradiance. After 2010, RCP4.5 simulates a rapid increase in $T_{\mathrm{s}}$, due to increasing concentrations of long-lived GHGs and decreasing emissions of aerosols and aerosol precursors (Lamarque et al., 2010).

\section{Results and discussion}

It is useful to briefly consider aerosol-induced changes in the global Hadley circulation, because these motivated the original hypothesis that aerosol forcing contributed to the observed rainfall increase in NWA (Rotstayn et al., 2007). Figure 4 shows the simulated modern-day minus pre-industrial
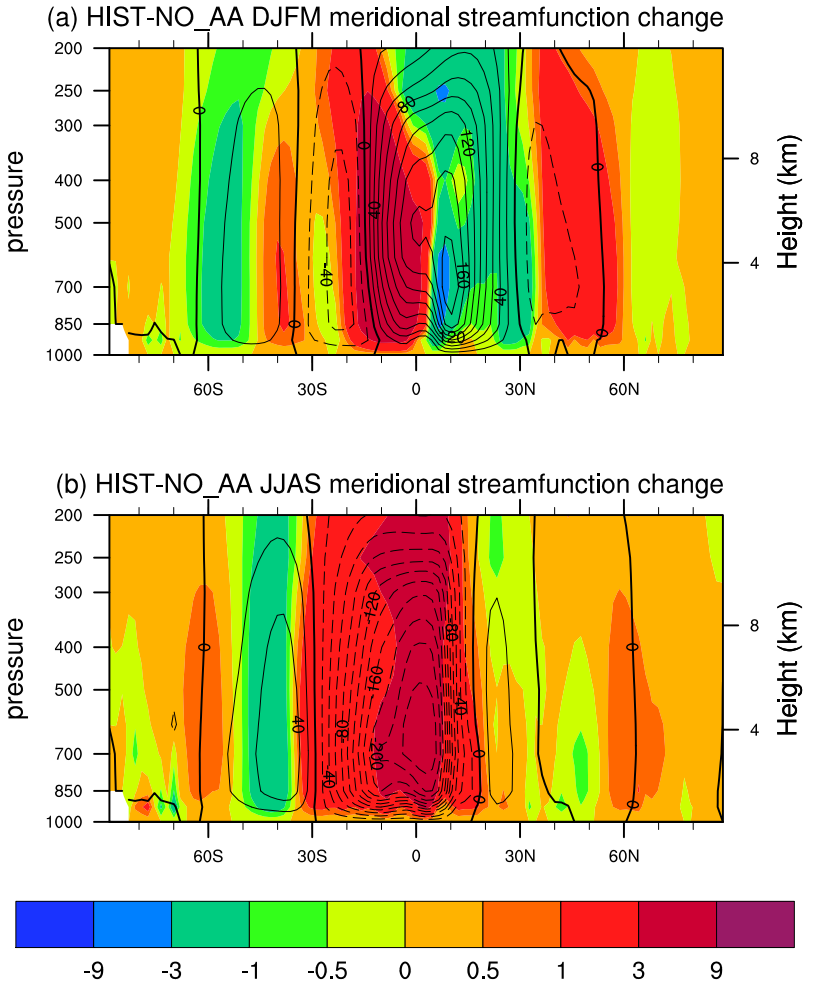

Fig. 4. Modern-day (1986-2005) minus pre-industrial (1850-1899) change in meridional streamfunction (shaded) from HIST minus NO_AA for (a) DJFM, (b) JJAS. Contours show the climatology from HIST, averaged over 1850-1899. Positive numbers denote clockwise circulation.

aerosol-induced change in the meridional streamfunction for DJFM and June-September (JJAS). The change in DJFM resembles a southward shift, whereas the change in JJAS resembles an overall weakening of the Hadley cell. The difference is possibly due to the fact that the stronger aerosol forcing north of the Equator is collocated with the ascending branch of the Hadley cell in JJAS, and the descending branch in DJFM. In qualitative terms the DJFM result is consistent with the idea that aerosol forcing could cause an increase of summer rainfall in areas south of the Equator, including Australia. We now focus on the Australasian region in more detail.

\subsection{Evaluation of mean state and variability}

Here we briefly evaluate the model's simulation of rainfall and circulation in the Australian region. Rainfall, surface temperature and sea-level pressure for summer and winter were previously evaluated by Rotstayn et al. (2010), based on a control run of CSIRO-Mk3.6 with modern-day forcing, and different aerosol emissions from those used in CMIP5. Modelled and observed climatological rainfall for DJFM are compared in Fig. 5. The broad pattern of Australian summer 


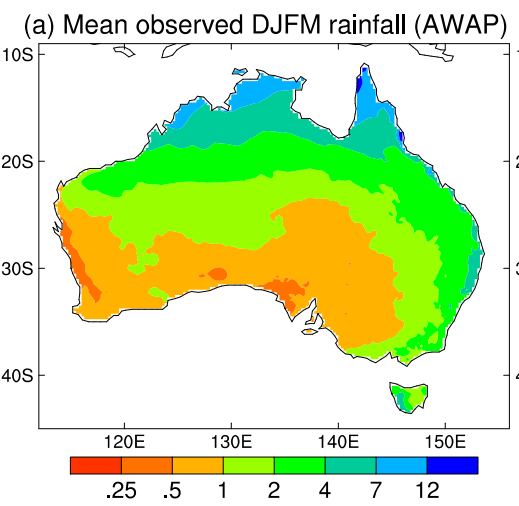

(b) Mean modelled DJFM rainfall (HIST)

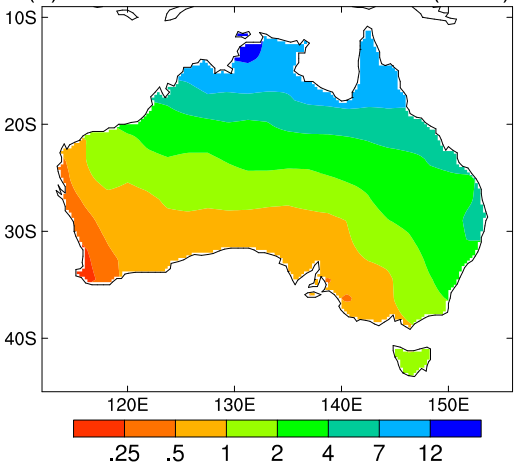

(c) Difference (HIST minus AWAP)

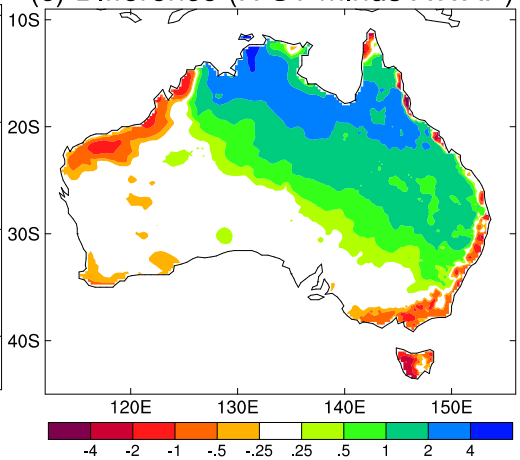

Fig. 5. DJFM rainfall, averaged over 1980 to 2005 (in mm per day): (a) observations from AWAP, (b) from the HIST ensemble mean, (c) HIST minus AWAP. The model output was interpolated to the finer $\left(0.25^{\circ}\right)$ AWAP grid prior to plotting.

rainfall is simulated rather well, but the differences in Fig. 5c show a number of biases. The model is generally too wet in the north, and too dry over Tasmania and along the coast in the north-west, south-west and south-east.

Figure 6 shows the DJFM climatologies of horizontal winds at $850 \mathrm{hPa}$ (vectors) and vertical pressure velocity at $500 \mathrm{hPa}$ (shading) from the HIST ensemble, and from NCEPDOE Reanalysis 2 (NCEP2; Kanamitsu et al., 2002). Some models biases are evident. To the east, there is a split intertropical convergence zone; this is a common problem in AOGCMs (e.g. Lin, 2007), and is also a manifestation of the Pacific equatorial cold tongue bias. The model has overly strong westerly winds in the equatorial eastern Indian ocean, overly strong ascent in the centre of the ITCZ, and weak subsidence over south-eastern Australia and part of south-east Asia. However, most of the broad features are well captured by the model. The wind vectors in both panels clearly show the Asian winter monsoon, the strong subtropical anticyclone in the southern Indian Ocean, and the monsoon shear line across northern Australia. The vertical velocity field shows ascent along the equator, and strong subsidence over Asia and the subtropics of the Southern Hemisphere.

Assessing the interannual variability in the model can provide insights into the realism of the simulated mechanisms. ENSO is a useful proxy for long-term changes in the Walker circulation associated with anthropogenic forcing, although there are differences in the underlying mechanism and associated patterns (Vecchi and Soden, 2007; Lu et al., 2008). In the next three figures, we show regressions of various quantities for DJFM against SST averaged over the Niño-3.4 region $\left(170-120^{\circ} \mathrm{W}, 5^{\circ} \mathrm{S}-5 \mathrm{~N}^{\circ}\right)$, hereafter Niño-3.4 SST. All quantities were linearly detrended before performing the regressions. For SST observations we use the $1^{\circ}$ gridded analysis from HadISST 1.1 (Rayner et al., 2003).

An anticyclonic circulation off the coast of NWA in austral summer has been identified in response to El Niño in reanalyses (Wang et al., 2003, 2008), and GCM simulations using prescribed SSTs and/or mixed-layer ocean models (Lau and Nath, 2000; Taschetto et al., 2011). Either explicitly or by implication, these studies also showed that anomalies associated with La Niña were similar, but with opposite polarities. Does the ENSO-related variability in our model show similar behaviour?

Figure 7 shows $850 \mathrm{hPa}$ winds for DJFM, regressed against Niño-3.4 SST, from the NCEP reanalysis and the HIST ensemble. A noticeable bias in the model is due to the Pacific equatorial cold tongue, which causes the equatorial westerly anomalies to extend too far to the west. The location and shape of the elongated anticyclonic anomaly off the coast of NWA are similar in the model and reanalysis, and also resemble the feature shown by Wang et al. (2003) (their Fig. 1c).

Figure 8 shows DJFM SST, regressed against Niño-3.4 SST, from observations and the HIST ensemble. The observations show the familiar horseshoe-shaped pattern of SST anomalies in the Pacific Ocean, as well as a warming of most of the Indian Ocean. The latter is substantially captured by the model, and is due to the "atmospheric bridge" from the Pacific Ocean (Klein et al., 1999; Alexander et al., 2002). The warming of the Indian Ocean can be mostly explained by decreases of cloudiness and wind speed during El Niño events, and anomalies of the opposite sign during $\mathrm{La}$ Niña events (Klein et al., 1999). The model shows the effect of the equatorial Pacific cold-tongue bias, with positive SST anomalies extending too far to the west. To the northwest of Australia, the region of positive SST anomalies is too small and too weak, and further south, the region of negative SST anomalies is too large and too strong. These negative anomalies can be explained by a strengthening of the Indonesian Throughflow and Leeuwin Current in La Niña years (Feng et al., 2008); these currents transport heat from the tropical Pacific warm pool, southward along the coast. The positive anomalies further north reflect weaker latent cooling of the ocean surface in El Niño years, due to weaker 
(a) 1980-2010 mean DJFM $850 \mathrm{hPa}$ winds and $500 \mathrm{hPa}$ omega, NCEP2

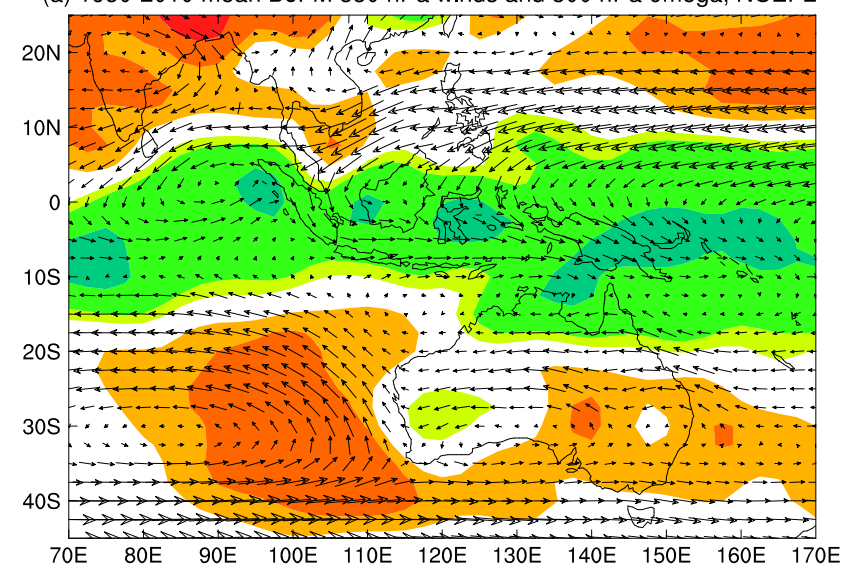

(b) 1980-2010 mean DJFM $850 \mathrm{hPa}$ winds and $500 \mathrm{hPa}$ omega, HIST

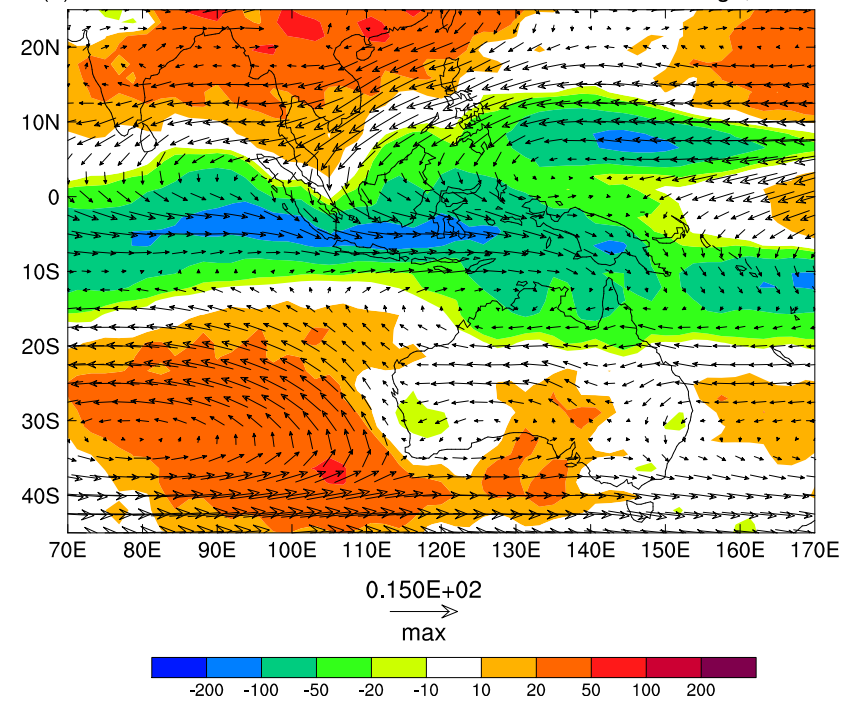

Fig. 6. Simulated mean $850 \mathrm{hPa}$ wind vectors $\left(\mathrm{m} \mathrm{s}^{-1}\right)$ and $500 \mathrm{hPa}$ vertical velocity (shading, $\mathrm{hPaday}^{-1}$ ) for DJFM, averaged over 1980 to 2010, (a) from the HIST ensemble, and (b) from NCEPDOE Reanalysis 2 . The maximum vector is shown below the plot.

monsoonal north-westerly winds; in La Niña years there is stronger latent cooling associated with stronger monsoonal north-westerly winds (Hendon, 2003; Hendon et al., 2012). The distortion of these features in Fig. 8b suggests that, while these competing processes are present in the model, the balance between them is not accurately captured.

Figure 9 shows DJFM rainfall over Australia, regressed against Niño-3.4 SST, from observations and the HIST ensemble. The modelled ENSO-rainfall relationship in Mk3.6 (Fig. 9b) is somewhat too strong over NWA, though it also tends to be too strong over much of the continent, including parts of north-eastern Australia. There is no clear evidence of a westward bias of the ENSO-rainfall relationship over Australia, as documented for the CMIP3 multi-model ensemble mean by Cai et al. (2011).
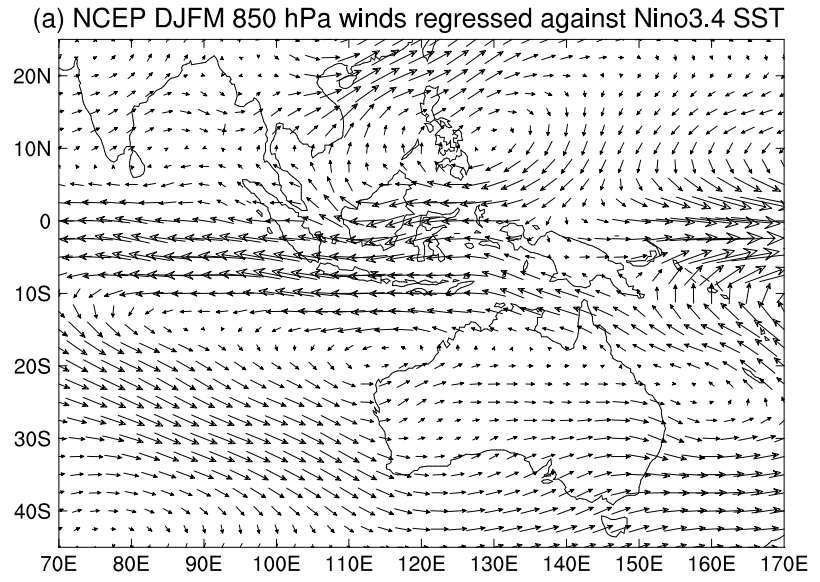

(b) HIST DJFM $850 \mathrm{hPa}$ winds regressed against Nino3.4 SST

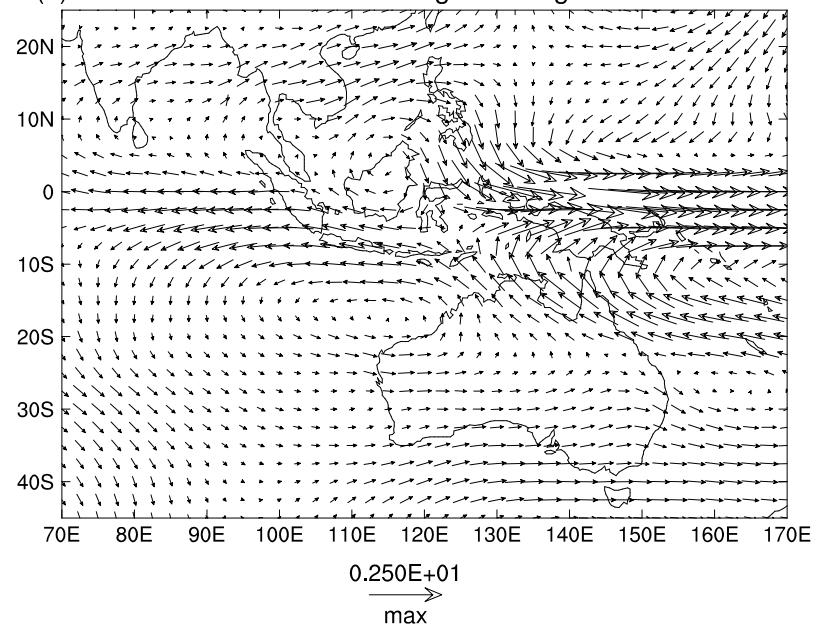

Fig. 7. DJFM $850 \mathrm{hPa}$ winds regressed against Niño-3.4 SST $\left(\mathrm{m} \mathrm{s}^{-1} \mathrm{~K}^{-1}\right)$ for the period 1951-2010, from (a) observations (HadISST and NCEP), and (b) the HIST ensemble. All data sets were linearly detrended before performing the regression.

\subsection{Simulated rainfall trends}

We briefly compare rainfall trends for both JJAS and DJFM over the wider Indo-Pacific region, to put the Australian results in a wider context. Statistical significance of ensemble means at each grid point is assessed using a two-sided t-test, taking the 10 individual trend values as independent data points (Deser et al., 2012). For the difference of two ensemble means at each grid point (e.g. HIST minus NO_AA), a two-sample t-test for the difference of the mean of two populations is used (Zar, 1996, chapter 8).

Figure 10 (left column) shows ensemble-mean rainfall trends from GHGAS, HIST and the aerosol-induced effect (HIST minus NO_AA) for JJAS. GHGAS (Fig. 10a) shows evidence of increasing monsoonal rainfall over parts of South and Southeast Asia, similar to the multi-model mean for $21 \mathrm{st}$ century projections in Meehl et al. (2007). GHGAS also 


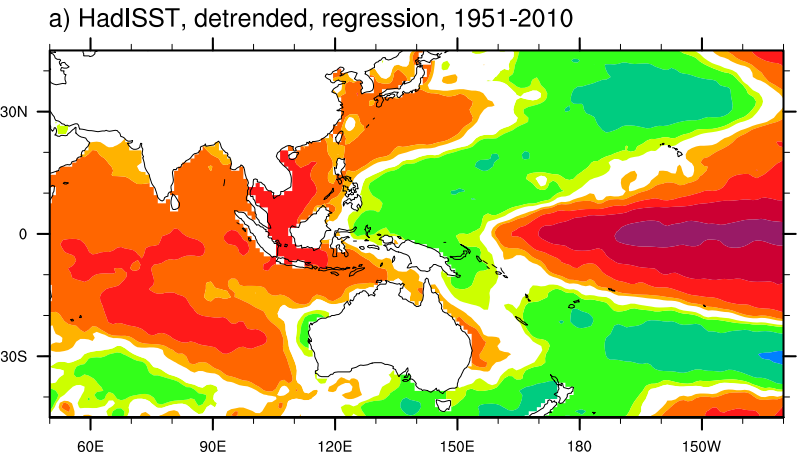

b) Mk36, detrended, regression, 1951-2010

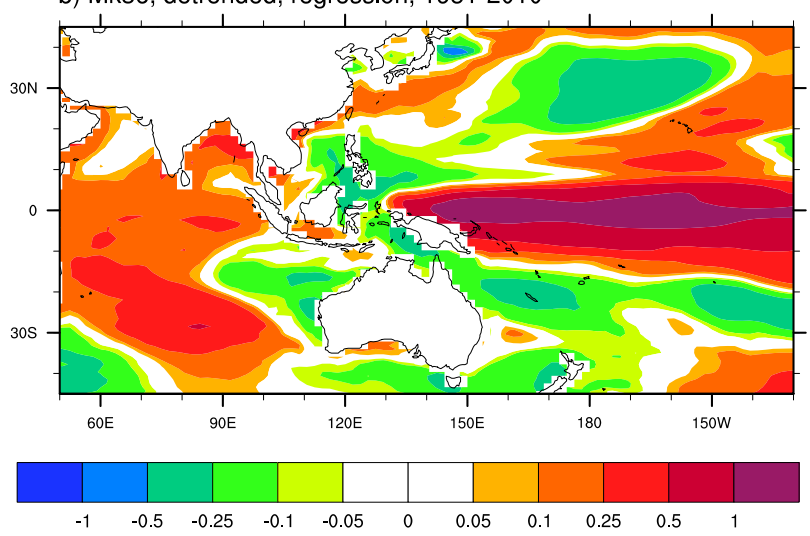

Fig. 8. DJFM gridpoint SST regressed against Niño-3.4 SST $\left(\mathrm{K} \mathrm{K}^{-1}\right)$ for the period 1951-2010, from (a) HadISST observations, and (b) the HIST ensemble. Both data sets were linearly detrended before performing the regression.

shows decreasing rainfall south of the equator over the Indian Ocean. Anthropogenic aerosol forcing (Fig. 10c) causes a decrease of rainfall over Southeast Asia and the tropical western Pacific. These are broadly similar to those reported recently by Bollasina et al. (2011), except that our model does not capture the observed rainfall decrease over centralnorthern India in HIST (Fig. 10e). The aerosol-induced effect in JJAS also shows a tendency for increasing rainfall south of the equator over the Indian Ocean; this appears to be consistent with earlier suggestions of a southward shift of tropical rainfall in response to regional forcing from Asian aerosols (Rotstayn et al., 2007). In terms of circulation, this corresponds to a southward shift and weakening of the upward branch of the local Hadley circulation; this is discussed further in Sect. 3.5.

In DJFM, the main features seen in Fig. 10 (right column) are quite different. In GHGAS, the dominant feature is an increase of rainfall over the equatorial western Pacific Ocean, and a horseshoe-shaped pattern of decreasing rainfall to its west, covering parts of Southeast Asia and Australia. The aerosol-induced effect in DJFM (Fig. 10d) resembles the inverse of the GHG-induced pattern, with a strong de- (a) AWAP

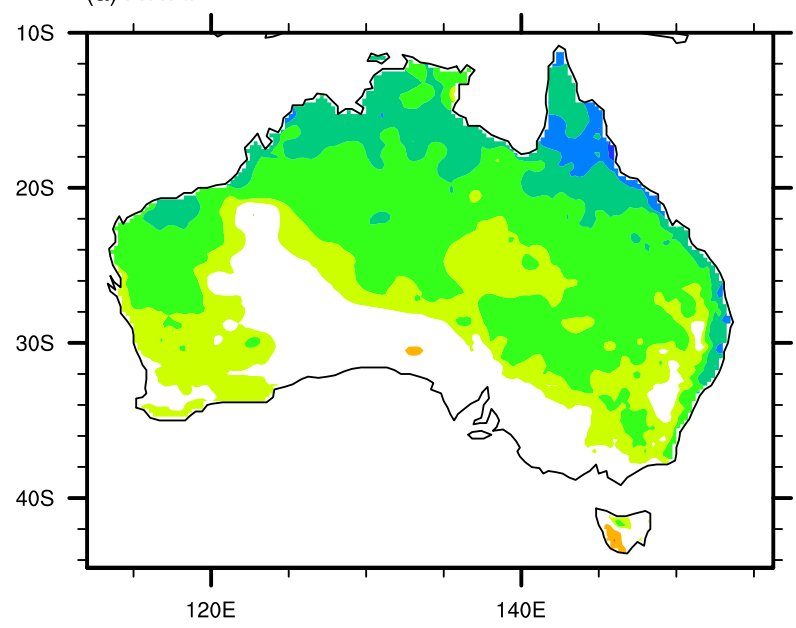

(b) Mk3.6
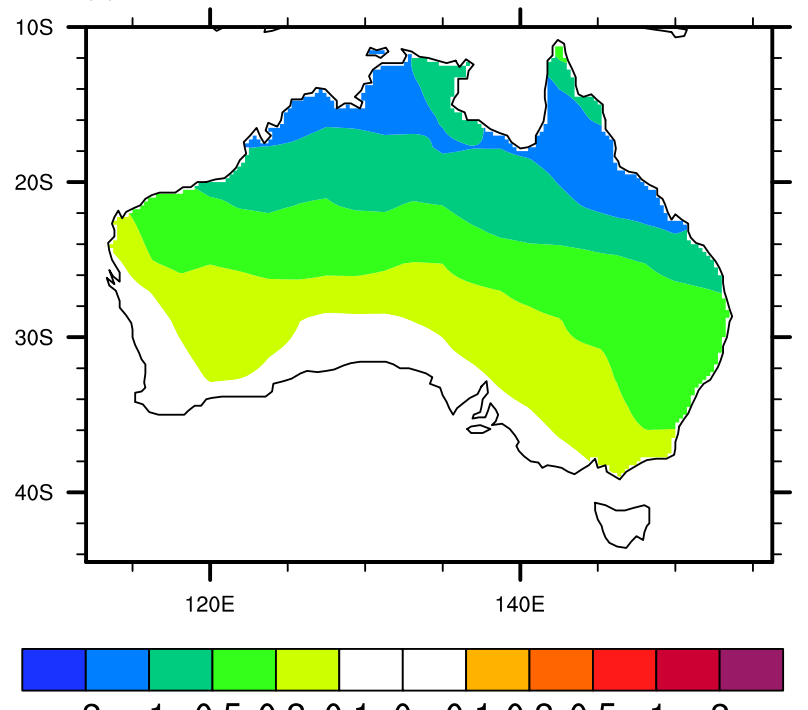

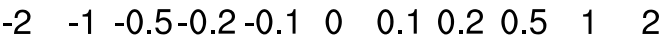

Fig. 9. DJFM rainfall regressed against Niño-3.4 SST $\left(\mathrm{mm} \mathrm{day}^{-1} \mathrm{~K}^{-1}\right.$ ) for the period 1951-2010, from (a) observations (AWAP and HadISST), and (b) the HIST ensemble. All data sets were linearly detrended before performing the regression. The model output was interpolated to the finer $\left(0.25^{\circ}\right)$ AWAP grid prior to plotting.

crease of rainfall over the equatorial western Pacific Ocean. The changes in DJFM are suggestive of an eastward (westward) shift in the upward branch of the Pacific Walker circulation in response to GHG (aerosol) forcing. Similar GHGand aerosol-induced changes have been noted before in other models (Xie et al., 2010; Bollasina et al., 2011). Over the Indian Ocean, GHGAS shows a westward shift of equatorial rainfall from the maritime continent towards the central Indian Ocean, and the aerosol-induced effect is again of opposite sign. In Fig. 10d, an area of decreasing rainfall centred on southern Borneo is likely a result of regional aerosol-induced 

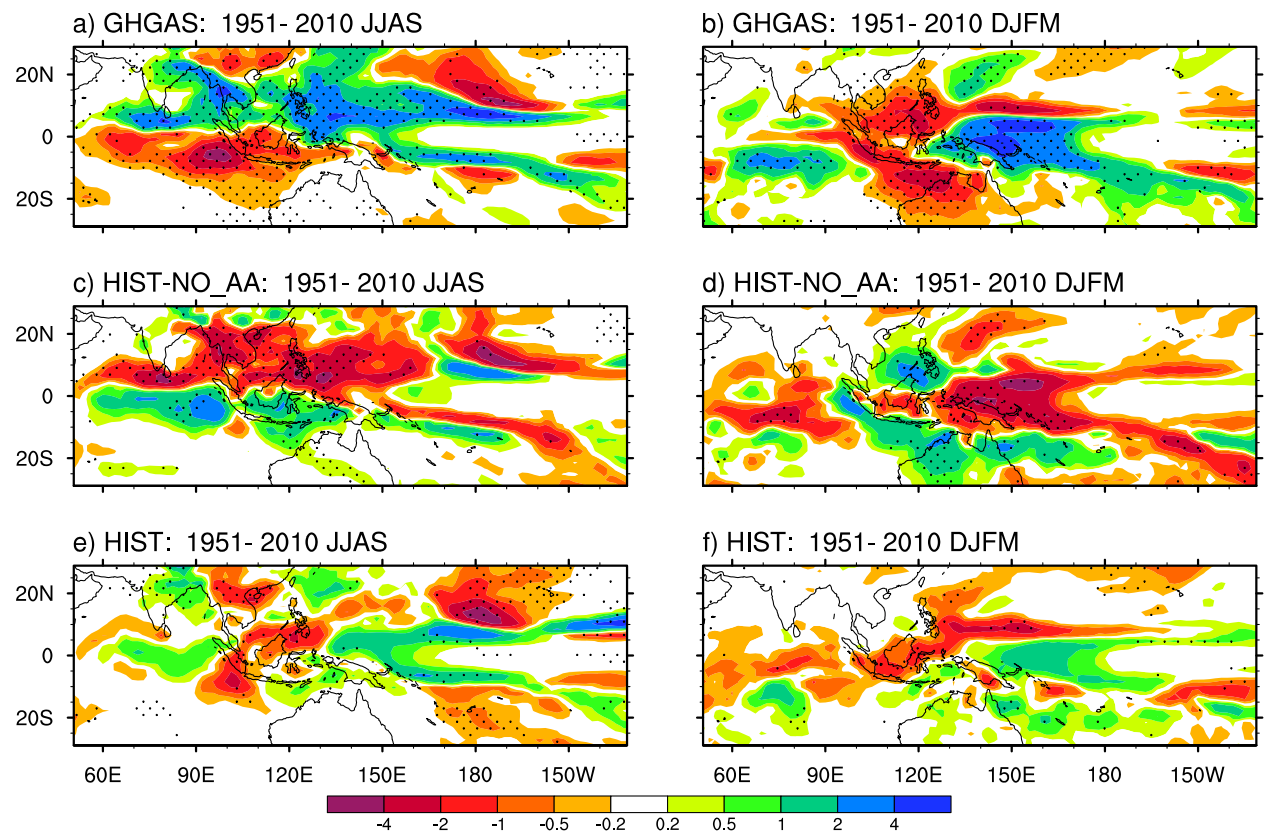

Fig. 10. Simulated rainfall trends $\left(\mathrm{mm} \mathrm{day}^{-1}\right.$ century $^{-1}$ ) for 1951-2010, from (a) GHGAS for JJAS, (b) GHGAS for DJFM, (c) HIST minus NO_AA for JJAS, (d) HIST minus NO_AA for DJFM, (e) HIST for JJAS, (f) HIST for DJFM. Stippled trends are significant at $5 \%$.

negative radiative forcing, which may suppress convection; this is present in the annual mean (Fig. 2) and also in DJFM (not shown).

It is interesting that in JJAS the regional rainfall response in both GHGAS and HIST minus NO_AA substantially resembles a meridional shift, with the aerosol-induced effect being (to first order) the opposite of the GHG-induced effect. Consistent with the idea that changes in the Hadley circulation are dynamically controlled (Ming and Ramaswamy, 2011), a plausible explanation is that the GHG-induced effect is a transient response, related to relatively rapid warming of the Asian continent, whereas the aerosol-induced effect is due to cooling caused by increasing aerosols in the Asian region. Thus, even though forcing from increasing long-lived GHGs is quasi-uniform in space, and anthropogenic aerosol forcing is very regional, the first-order rainfall response is similar but of opposite sign.

However, in DJFM the aerosol- and GHG-induced regional rainfall responses show little evidence of a meridional shift, and more closely resemble a change in the Walker circulation. A plausible explanation is that, in JJAS, changes in the local Hadley circulation are enhanced by changes in latent heating in the region of the Asian summer monsoon. However, in DJFM, there is insufficient latent heating to provoke a large-scale meridional shift in the local Hadley circulation and the associated rainfall. In this season, increasing long-lived GHGs may provoke changes in the Walker circulation via the thermodynamic mechanism discussed in the Introduction, and it is plausible that anthropogenic aerosols oppose this effect (Ming and Ramaswamy, 2011). These changes in circulation are discussed further in Sects. 3.4 and 3.5.

We now focus in more detail on DJFM, when there has been a significant increase of rainfall over Australia's northwest in recent decades (Fig. 1). The time history of this increase is plotted in Fig. 11, which shows an increasing trend since roughly the middle of the 20th century. The shorter (30and 40-yr) trends are not significant, but their magnitudes are comparable to that of the 60-yr trend from 1951 to 2010. Note that there was a rainfall minimum in the early 1950s, so trends beginning in 1951 will be relatively large.

We now compare ensemble-mean, projected and historical rainfall trends for DJFM. Figure 12 shows ensemble-mean rainfall trends over Australia from RCP4.5 (2011-2100). There are substantial, statistically significant decreases over most of the continent, and especially in the tropics. In contrast, HIST (Fig. 13a) shows modest increases over some areas (including NWA) during 1951-2010, though these are mostly not significant.

How are these differences between projected and historical rainfall trends to be reconciled? To clarify this, the other panels of Fig. 13 show historical rainfall trends under different forcing assumptions. Rainfall trends in GHGAS are similar to those in RCP4.5, though of smaller magnitude; this is consistent with the expected dominant role of GHG forcing in RCP4.5. (It should be noted that RCP4.5 also includes declining anthropogenic aerosols, and a reversal of stratospheric ozone depletion.) NO_AA is similar 


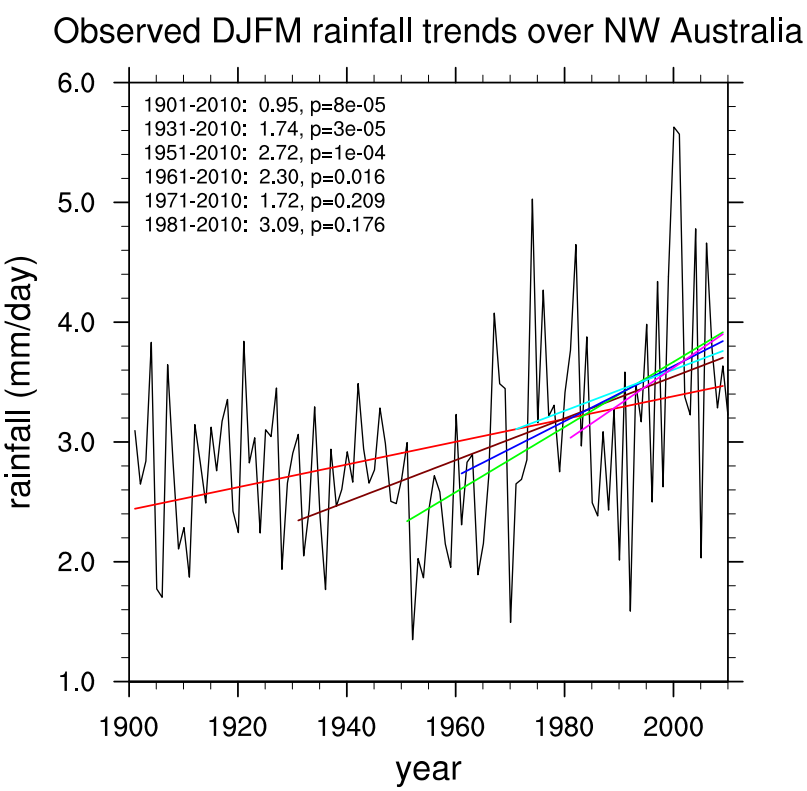

Fig. 11. Time series of observed DJFM rainfall from AWAP, averaged over land in the region $10^{\circ} \mathrm{S}$ to $25^{\circ} \mathrm{S}, 110^{\circ} \mathrm{E}$ to $135^{\circ} \mathrm{E}$ (shown in Fig. 1). Trend lines are fitted for the last 110, 80, 60, 50, 40 and $30 \mathrm{yr}$; the magnitude of each trend (in $\mathrm{mm} \mathrm{day}^{-1}$ century ${ }^{-1}$ ) and its level of significance are shown in the upper-left corner of the plot.

to GHGAS, though the negative rainfall trends are somewhat weaker. Bearing in mind that NO_AA is the same as GHGAS with the addition of natural and ozone forcing, this can be understood by reference to natural and (especially) ozone-induced changes. Rainfall trends in Fig. 13d (NAT) are weakly positive over substantial areas of Australia, though mostly not significant. Interestingly, the ozoneinduced trends in Fig. 13e (HIST minus NO_OZ) are mostly positive, and are also significant over substantial areas.

The ozone-induced rainfall changes over Australia are part of a broader rainfall increase across the low latitudes of the Southern Hemisphere (not shown). This effect is similar to that obtained by Kang et al. (2011) using two models. They found that Antarctic ozone depletion causes a poleward shift of the extratropical westerly jet, which in turn induces a poleward shift of the subtropical edge of the Hadley cell. The poleward shift of this edge drives anomalous upper-level mass divergence between $15^{\circ} \mathrm{S}$ and $35^{\circ} \mathrm{S}$, and this causes anomalous rising motion in the subtropics. Our model appears consistent with the result from Kang et al. (2011) regarding the importance of ozone changes for understanding recent summer rainfall trends in the Southern Hemisphere. One caveat is that NO_OZ suppresses changes in both stratospheric and tropospheric ozone, so in principle our simulations are not designed to distinguish between these effects. In view of this, and the fact that our main focus is to contrast the effects of changes in aerosols and long-lived GHGs, we will not further analyse the effects of ozone changes,

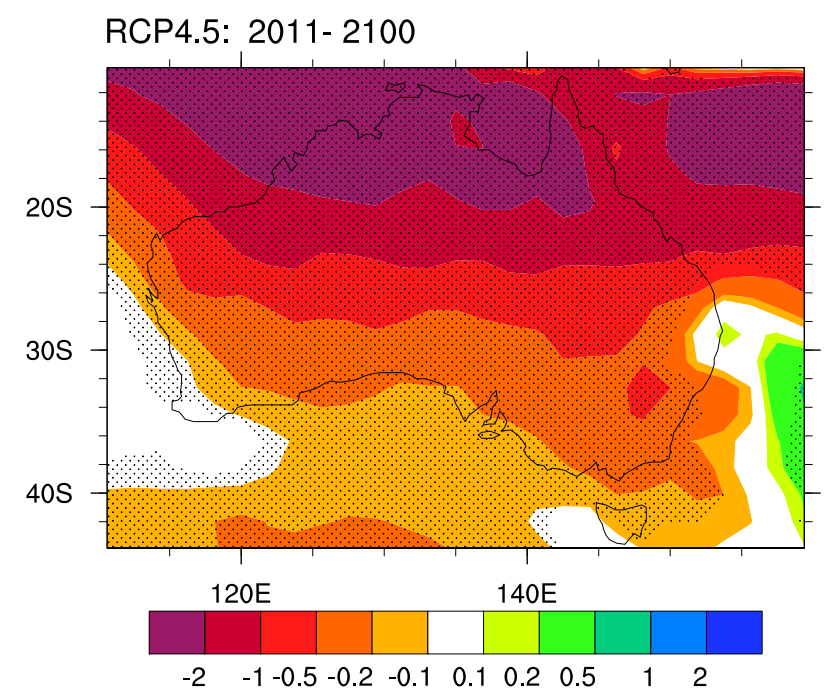

Fig. 12. Simulated DJFM rainfall trends $\left(\mathrm{mm} \mathrm{day}^{-1}\right.$ century $\left.^{-1}\right)$ from RCP4.5 (2011-2100). Stippled trends are significant at 5\%.

The aerosol-induced rainfall changes in Fig. 13f (HIST minus NO_AA) indicate that, in CSIRO-Mk3.6, aerosol forcing has opposed the effects of a GHG-induced decrease of Australian summer rainfall. The mechanisms will be investigated in Sect. 3.4.

\subsection{Comparison of observed and simulated rainfall trends}

Figure 14 compares observed and modelled trends in rainfall, averaged over the same area of NWA as used in Fig. 11. Individual 1951-2010 trends from the 10-member forced ensembles, and 440 unforced 60 -yr trends from the $500-\mathrm{yr}$ preindustrial control run (piControl), are shown as small black dots. (These were calculated using a moving $60-\mathrm{yr}$ window over the 500-yr run.) The observed $60-y r$ trend $(2.72 \mathrm{~mm}$ per day per century, shown as a red line) is not reproduced by any of the 440 unforced trends.

If the natural variability of the model is comparable to or larger than that in the observations, this would suggest there is a forced component in the observed trend. Interannual variability appears to be somewhat overestimated by the model; the standard deviation of the 499 individual (detrended) DJFM rainfall values in piControl is $1.31 \mathrm{~mm}$ per day, larger than the observed value of $0.75 \mathrm{~mm}$ per day for the detrended (1901-2010) time series. Decadal variability can be estimated by taking the standard deviation of 11-yr running means of the DJFM rainfall time series: in piControl, the standard deviation is $0.38 \mathrm{~mm}$ per day, whereas the detrended (raw) observed time series has standard deviation of $0.32(0.43) \mathrm{mm}$ per day. It is not obvious whether the detrended or raw observed time series provides a more realistic comparison: if we assume that the observed trend is entirely 

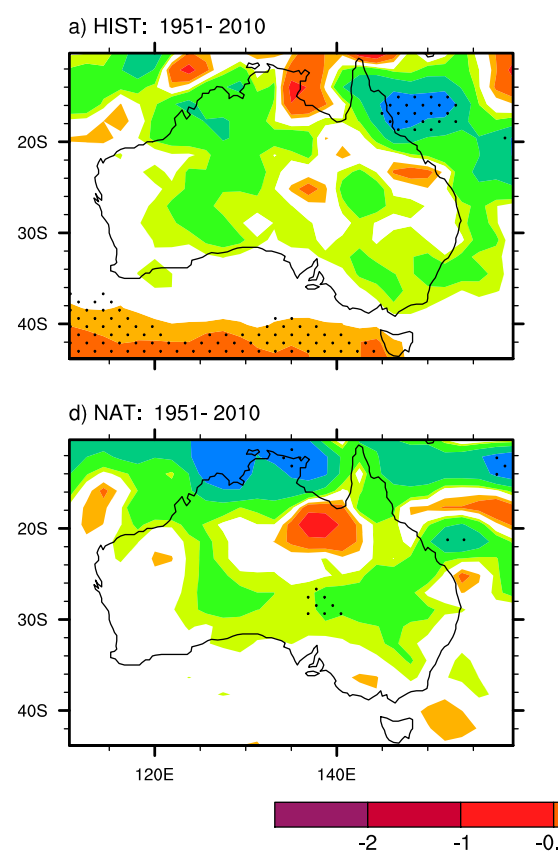

b) GHGAS: $1951-2010$

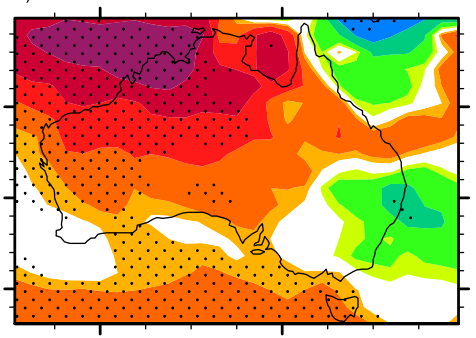

e) HIST-NO_OZ: $1951-2010$

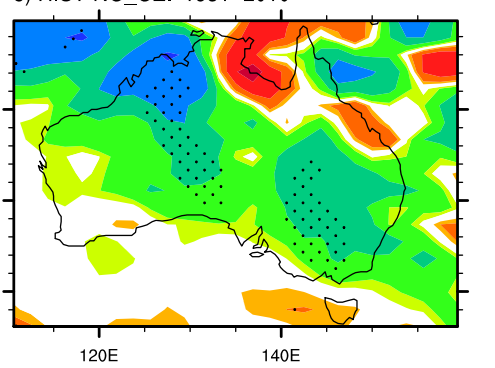

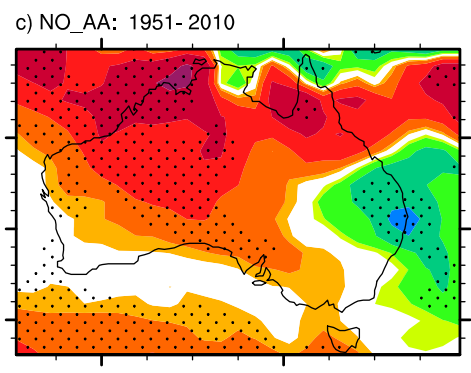

f) HIST-NO_AA: 1951- 2010

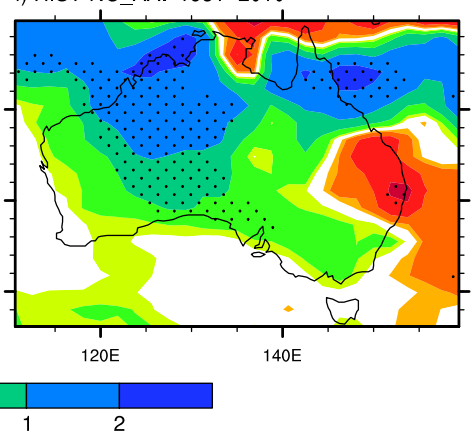

Fig. 13. Simulated DJFM rainfall trends $\left(\mathrm{mm}^{-1}\right.$ day $^{-1}$ century $^{-1}$ ) for 1951-2010, from (a) HIST, (b) GHGAS, (c) NO_AA, (d) NAT, (e) HIST minus NO_OZ, (f) HIST minus NO_AA. Stippled trends are significant at $5 \%$.

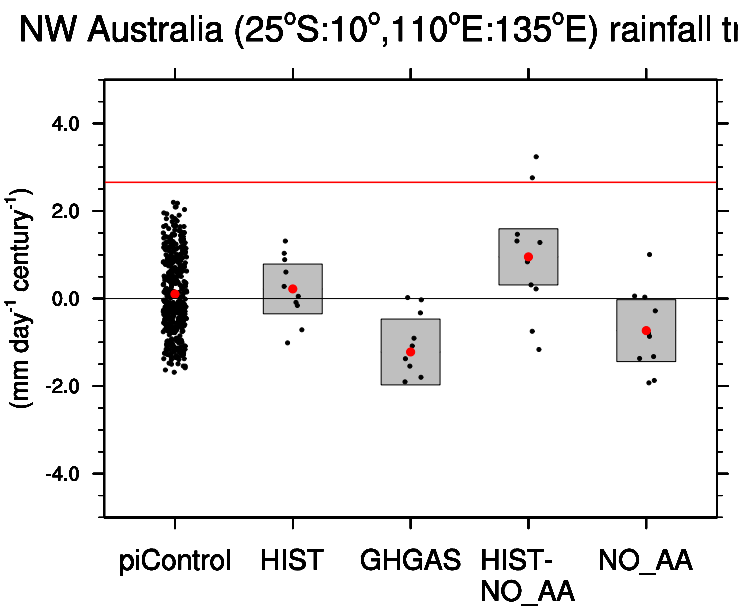

Fig. 14. 60-yr DJFM rainfall trends, averaged over land in the region $10^{\circ} \mathrm{S}$ to $25^{\circ} \mathrm{S}, 110^{\circ} \mathrm{E}$ to $135^{\circ} \mathrm{E}$ (shown in Fig. 1). The horizontal red line shows the observed 1951-2010 trend from AWAP. The small black dots show individual 1951-2010 trends from the 10member forced ensembles (HIST, GHGAS and NO_AA) and 440 60-yr trends from the 500-yr preindustrial control run (piControl). For the case of HIST minus NO_AA, the 10 small black dots represent trends formed by pairing run $n$ of HIST with run $n$ of NO_AA. The large red dots show the ensemble-mean trend from each experiment, and the grey bars show the $95 \%$ confidence interval, based on a one-sample t-test for HIST, GHGAS and NO_AA, and two-sample t-test for HIST minus NO_AA. due to natural variability, then the raw time series might be more appropriate. However, even the larger value from the raw time series $(0.43 \mathrm{~mm}$ per day) would indicate only a small underestimate of decadal variability by the model. Thus, based on this simple measure of decadal variability, our results suggest there is likely to be a forced component in the observed trend.

However, the model does not simulate the observed rainfall increase in response to "all forcings" (HIST), even in a single ensemble member. This is puzzling, given that the model's decadal variability appears to be reasonable. One explanation is that because the simulated forcing and response for each of the forcing agents in HIST are presumably inaccurate to varying degrees, this would cause the response to the total forcing to also be inaccurate. The aerosol forcing is itself highly uncertain; we also show in Sect. 3.5 that although aerosol-induced changes in regional circulation resemble the inverse of the GHG-induced pattern to first order, there are also some marked differences between their respective patterns of response. Further, as we showed in Sect. 3.2, ozone changes induce an increase of rainfall over NWA in the model, and comparison with Kang et al. (2011) suggests that the associated circulation changes are driven from the high latitudes of the Southern Hemisphere; this differs from the mainly tropical mechanisms that we discuss in relation to aerosols and long-lived GHGs. Another possible explanation is that the observed time period (of order $100 \mathrm{yr}$ ) may be too short to yield a reliable estimate of decadal variability: breaking up piControl into five 100-yr blocks, and calculating the 

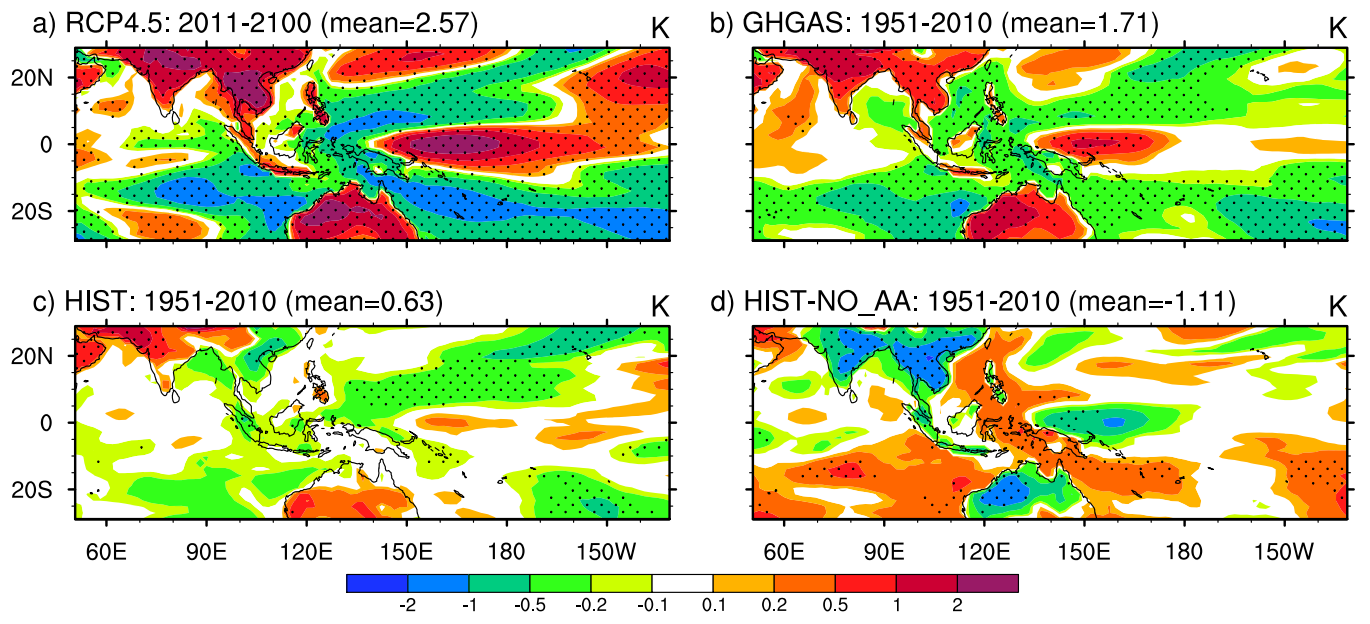

Fig. 15. Ensemble-mean DJFM trends of $T_{\mathrm{S}}$ with the low-latitude $\left(30^{\circ} \mathrm{S}-30^{\circ} \mathrm{N}\right)$ mean $T_{\mathrm{S}}$ trend subtracted (i.e. $\left.T_{\text {rel }}\right)$, from (a) RCP4.5 (20112100), (b) GHGAS (1951-2010), (c) HIST (1951-2010), (d) HIST minus NO_AA (1951-2010). The low-latitude mean $T_{\mathrm{S}}$ trend for each ensemble is shown in its header $\left(\mathrm{K}_{\text {century }}{ }^{-1}\right)$. Stippled trends are significantly different from the low-latitude mean at $5 \%$.

standard deviation of the 11-yr running means for each block gives a range of 0.32 to $0.46 \mathrm{~mm}$ per day. Rainfall observations in NWA are quite sparse, especially in the early 20th century, and this adds to the uncertainty.

As expected from Fig. 13, GHGAS and HIST minus NO_AA show more substantial rainfall trends than HIST. 95\% confidence intervals for GHGAS and HIST minus NO_AA confirm that the ensemble-mean GHG- and aerosolinduced rainfall trends are significantly different from zero, and of opposite signs. For HIST minus NO_AA, even though we did not assume that the individual runs are paired when testing for significance, we have plotted individual trend values by pairing run 1 from HIST with run 1 from NO_AA, and so on. (The runs that were paired in this way do share a common branch time from the pre-industrial control run.) Two of the individual "HIST minus NO_AA" trends are larger than the observed trend value. In other words, the aerosol-induced effect (in isolation) plus natural variability could explain the observed rainfall trend in our model. However, given that the real climate system includes forcing from both aerosols and GHGs, this does not amount to an attribution of the NWA rainfall trend.

Bearing these caveats in mind, insights into possible causes of the NWA rainfall trend can still be gained by investigating the mechanism in the model and in observations. This is the topic of the remainder of this section.

\subsection{Simulated and analysed changes in circulation}

What is the mechanism by which changes in long-lived GHGs and aerosols exert effects of opposite sign on Australian summer rainfall in CSIRO-Mk3.6? We address this question by investigating the changes in circulation associated with each forcing agent.
Changes in tropical circulation are often driven by SST anomalies relative to the surrounding ocean (Xie et al., 2010; Watterson, 2010). An important underlying mechanism is the generation of lower-tropospheric pressure gradients, which induce moisture convergence (Lindzen and Nigam, 1987). Thus we compare trends in $T_{\mathrm{s}}$, after subtraction of the mean low-latitude $\left(30^{\circ} \mathrm{S}\right.$ to $\left.30^{\circ} \mathrm{N}\right)$ trend from each ensemble (hereafter referred to as $T_{\text {rel }}$ ). Figure 15 shows that $T_{\text {rel }}$ trends in GHGAS qualitatively share many features with the strong GHG-driven pattern in RCP4.5: there is enhanced warming over continental areas, a result typical of the response of GCMs to increasing GHGs (Meehl et al., 2007) and also in the western and central equatorial Pacific (Liu et al., 2005; DiNezio et al., 2009), though the latter feature is more extended to the east in RCP4.5. There is relatively less warming in the Southern Hemisphere than in the Northern Hemisphere, consistent with the multi-model mean in Meehl et al. (2007), and also in the eastern tropical Indian Ocean (Xie et al., 2010). More rapid warming in the Northern Hemisphere is a robust feature of transient simulated climate change; it is related to the larger proportion of land in the Northern Hemisphere, and more efficient downward transport of heat by the oceans of the Southern Hemisphere (Boer et al., 2000).

$T_{\text {rel }}$ trends in HIST (Fig. 15c) are much weaker than those in GHGAS and RCP4.5, and the features identified above are absent or much reduced. The aerosol-induced effect in Fig. 15d highlights that this is largely due to the inclusion of aerosol forcing in HIST. Several features of Fig. 15d are of opposite sign to those in Fig. 15a and b: over South and East Asia there is relative cooling, due to negative forcing by anthropogenic aerosols. In contrast, relative cooling over tropical Australia is caused primarily by increasing rainfall (Fig. 13f), since aerosols there are mainly associated with 

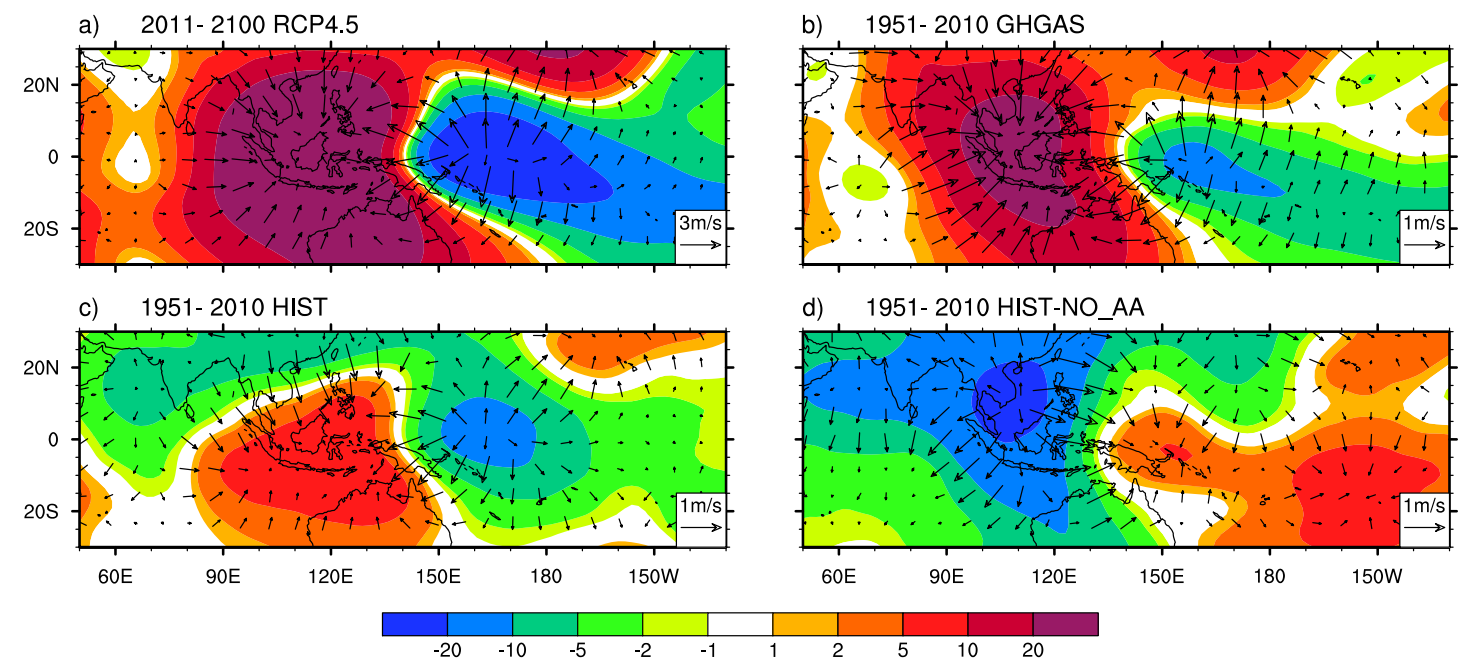

Fig. 16. Ensemble-mean DJFM trends of velocity potential $\left(10^{5} \mathrm{~m}^{2} \mathrm{~s}^{-1}\right.$ century $\left.{ }^{-1}\right)$ and divergent wind vectors $\left(\mathrm{m} \mathrm{s}^{-1}\right.$ century $\left.{ }^{-1}\right)$ at $200 \mathrm{hPa}$, from (a) RCP4.5 (2011-2100), (b) GHGAS (1951-2010), (c) HIST (1951-2010), (d) HIST minus NO_AA (1951-2010). The largest vector is shown in the lower-right corner of each panel; note different scaling of vectors in RCP4.5.

dust or savanna burning during the dry season. In the western equatorial Pacific, there is relative cooling instead of enhanced warming. In the Southern Hemisphere, the pattern is also very different, with relative warming over much of the Pacific Ocean, and in the tropical eastern Indian Ocean.

Figure 16 shows trends of velocity potential and divergent wind vectors at $200 \mathrm{hPa}$; with the sign convention used here, cool (warm) colours denote centers of increasing (decreasing) upper-level divergence and ascending motion. RCP4.5 shows increasing upper-level divergence over the tropical central-western Pacific, and decreasing upper-level divergence over the maritime continent. The pattern in GHGAS resembles a slightly weaker version of the strong GHGforced trend seen in RCP4.5, and the trend pattern in HIST is weaker again. The aerosol-induced effect (Fig. 16d) has the opposite polarity, and suggests that the weaker trend pattern in HIST compared to GHGAS is due to the offsetting effect of aerosol forcing.

Another view of the circulation changes induced by changes in long-lived GHGs and anthropogenic aerosols is given by trends in $850 \mathrm{hPa}$ wind vectors and $500 \mathrm{hPa}$ vertical velocity (Fig. 17). The wind trends show that in GHGAS, there is weaker convergence of zonal winds over the Indonesian region, consistent with a weakening Walker circulation, whereas the reverse is true for the aerosol-induced effect in panel $b$. The changes in equatorial zonal winds in both ocean basins are driven by an increasing pressure gradient towards the Indonesian region in GHGAS, and vice versa in HIST minus NO_AA (not shown); this is similar to the findings of Vecchi and Soden (2007) and Bollasina et al. (2011).

The horseshoe-shaped vertical-velocity trend patterns in Fig. 17 are broadly consistent with the DJFM rainfall trends in Fig. 10. They also confirm the eastward (westward) shift of the main equatorial convection centre in response to GHG (aerosol) forcing. After allowing for the equatorial Pacific cold tongue bias, which causes the equatorial Pacific anomalies to extend too far west towards Indonesia, the pattern in GHGAS (HIST minus NO_AA) resembles an El Niñolike (La Niña-like) anomaly pattern for austral summer (e.g. Wang et al., 2003, their Fig. 1c). This includes the trends over northern Australia and the southern Indian Ocean, and the anticyclonic (cyclonic) circulation trend pattern off the coast of NWA, which we showed in Fig. 7; we shall return to these regional aspects below.

The eastward shift of the main equatorial convection centre in response to GHG forcing (Figs. 16 and 17) is similar to that shown previously for an ensemble of CMIP3 GCMs forced by increasing GHGs (Vecchi and Soden, 2007). They related these changes to a weakening of the tropical circulation (and especially the Walker circulation), consistent with an increase in lower-tropospheric water vapour in a warmer climate (Held and Soden, 2006; Zhang and Song, 2006).

The modelled GHG-induced changes in equatorial SSTs can be substantially understood in terms of changes in the Walker circulation (Vecchi and Soden, 2007; DiNezio et al., 2009; Xie et al., 2010). A weaker Walker circulation gives weaker convergence of near-surface zonal winds over the Indonesian region. Over the eastern Indian Ocean, anomalous equatorial easterlies occur, with an increase in upwelling and a shallowing thermocline. These oceanic changes also occur in our model in response to increasing GHGs (not shown); they contribute to the relative cooling off the coasts of Java and Sumatra in Fig. 15a and b. This feature is strong in austral winter and spring, when the climatological southeasterly winds that flow along the coastlines of Sumatra and Java induce upwelling and a shallow thermocline and permit an 
(a) 1951-2010 DJFM trends in $850 \mathrm{hPa}$ winds and $500 \mathrm{hPa}$ omega, GHGAS

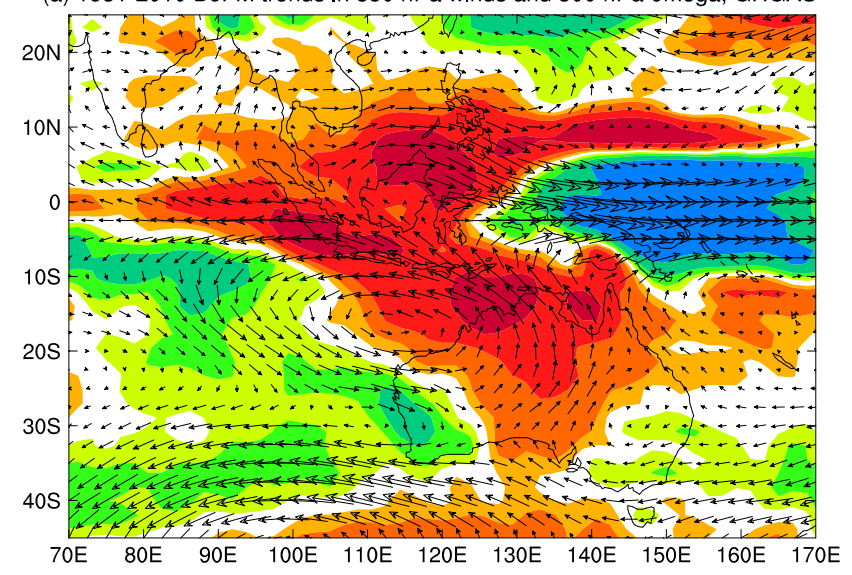

(b) 1951-2010 DJFM trends in $850 \mathrm{hPa}$ winds and $500 \mathrm{hPa}$ omega, HIST - NO_AA

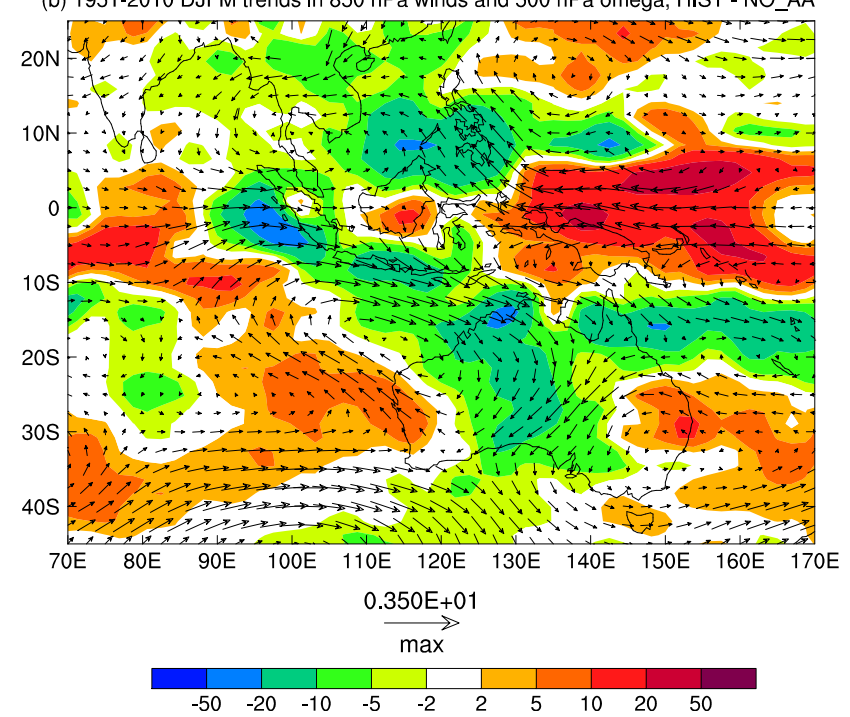

Fig. 17. Simulated 1951-2010 DJFM trends in $850 \mathrm{hPa}$ wind vectors $\left(\mathrm{m} \mathrm{s}^{-1}\right.$ century $^{-1}$ ) and $500 \mathrm{hPa}$ vertical velocity (shading, $\mathrm{hPa} \mathrm{day}^{-1}$ century $^{-1}$ ), for (a) GHGAS, (b) HIST minus NO_AA. The maximum vector is shown below the plot.

air-sea positive feedback process known as Bjerknes feedback (Saji et al., 1999; Schott et al., 2009). The SST anomaly then decays during austral summer.

The enhanced Pacific equatorial warming due to increasing GHGs in 11 AOGCMs was studied in detail by DiNezio et al. (2009). Enhanced warming along the equator was mainly due to changes in zonal and meridional oceanic heat advection, driven by a slowing down of the Pacific Walker circulation. They also found that ocean dynamical changes act to reduce the net heating in the east, and enhance it in the west. This explains why models simulate enhanced equatorial warming, rather than El-Niño-like warming, in response to a weaker Walker circulation. It is plausible that similar mechanisms occur in our runs, though further analysis would be needed to confirm this.
We now return to Fig. 17, which shows some notable changes in circulation in the Australian region. In particular, off the coast of NWA, there is an anticyclonic (cyclonic) circulation trend in GHGAS (HIST minus NO_AA). An effect of this circulation trend is to weaken the monsoonal flow across the north coast of Australia in GHGAS, and strengthen it in HIST minus NO_AA. Trends in RCP4.5 (not shown) show similar patterns to those in GHGAS, but are of larger magnitude.

The centres of the circulation trends off the coast of NWA are also very close to the centres of the regression patterns shown in Fig. 7. In particular, the tropical regression pattern in Fig. $7 b$ closely resembles the trend pattern in GHGAS (Fig. 17a), which suggests that the mechanism underlying the GHG-forced circulation changes in the tropics may be similar to that in ENSO. We will return to this point in Sect. 3.5. However, note that the patterns in the midlatitudes (e.g. over southern Australia) are very different, reflecting a broadening of the Hadley circulation in response to forcing from long-lived GHGs, and a narrowing during El Niño (Lu et al., 2008).

It is noticeable that the trends in vertical velocity $(\omega)$ at $500 \mathrm{hPa}$ are offset from the centres of the circulation trends in Fig. 17, in common with the results of Wang et al. (2003), who analysed interannual variations associated with ENSO. This can be explained in terms of Sverdrup vorticity balance (e.g. Rodwell and Hoskins, 2001),

$\beta v \approx f \frac{\partial \omega}{\partial p}$,

which expresses conservation of potential vorticity. Here, $v$ is meridional wind, $p$ is pressure, $f$ is the Coriolis parameter, and $\beta$ is its meridional gradient. Equation (1) implies that poleward motion is associated with ascent in the midtroposphere ("stretching" of the air column), whereas equatorward motion is associated with subsidence. This agrees well with the vertical velocity trends of opposite sign to the north-east and south-west of the horizontal circulation features centred off the coast of NWA in Fig. 17.

We also calculated trends of moisture transport $(q \boldsymbol{V})$ and moisture convergence $-\nabla \cdot(q \boldsymbol{V})$, and vertically integrated these through the depth of the atmosphere for GHGAS and HIST minus NO_AA (Fig. 18). The calculation is based on six-hourly instantaneous fields of specific humidity $(q)$ and horizontal winds $(\boldsymbol{V})$. Associated with the circulation trends shown in Fig. 17, there is a decreasing trend of moisture convergence over NWA in GHGAS, and an increasing trend in HIST minus NO_AA. The streamlines suggest that in HIST minus NO_AA, the source of increasing moisture for NWA comes from both the equatorial western Pacific and south of the equator in the central Indian Ocean; both of these areas show a decreasing rainfall trend (Fig. 10d) and a trend of increasing subsidence (Fig. 17b). The converse applies in GHGAS. 
(a) 1951-2010 DJFM moisture convergence trend, GHGAS

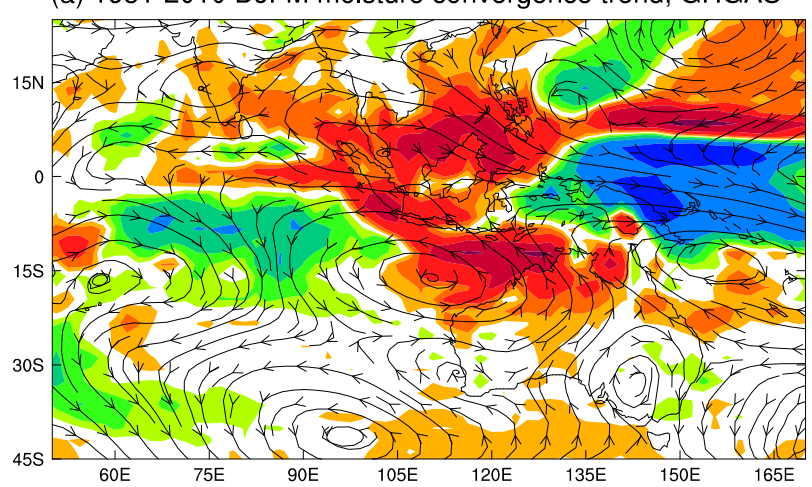

(b) 1951-2010 DJFM moisture convergence trend, HIST minus NO_AA

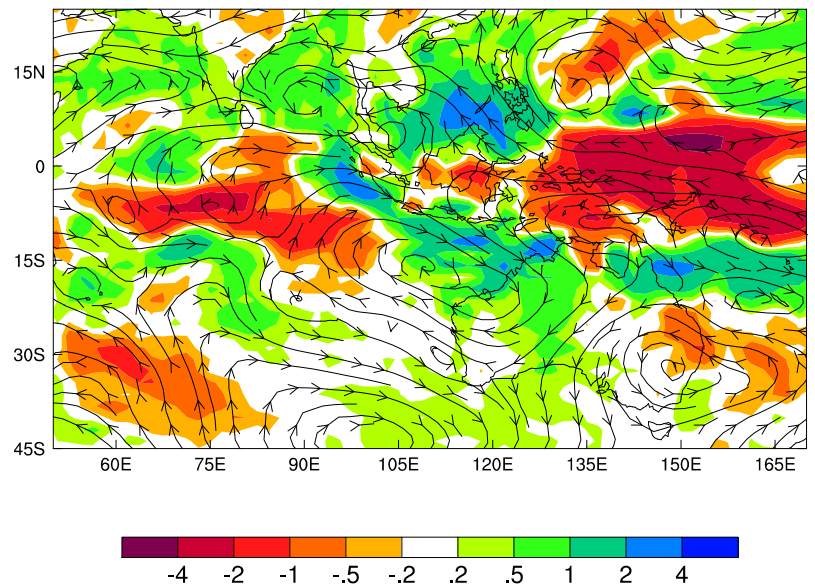

Fig. 18. Simulated 1951-2010 DJFM trends in moisture convergence (shading, in $\mathrm{mm} \mathrm{day}^{-1}$ century $^{-1}$ ) and moisture transport (streamlines), for (a) GHGAS, (b) HIST minus NO_AA.

Is there evidence for a cyclonic circulation trend off the coast of NWA in reanalyses? We use data from the ERAInterim Reanalysis (Dee et al., 2011), NCEP/NCAR Reanalysis 1 (NCEP1; Kalnay et al., 1996) and NCEP-DOE Reanalysis 2 (NCEP2; Kanamitsu et al., 2002). Of these, only NCEP1 provides data prior to the advent of satellite retrievals in 1979. However, various discrepancies have been noted in NCEP1, especially prior to the late 1970 s (e.g. Wu et al., 2005), so we calculate trends from NCEP1 both for the full 60-yr analysis period (1951-2010) and for 1980-2010 (i.e. December 1979 to March 2010).

Figure 19 shows trends in DJFM horizontal winds at $850 \mathrm{hPa}$ and vertical velocity at $500 \mathrm{hPa}$ from each reanalysis. All the analysed trends for 1980-2010 show a cyclonic circulation anomaly off the coast of NWA, and a similar feature is also evident in the 1951-2010 trend from NCEP1. The cyclonic trend anomaly for 1951-2010 is offset slightly to the north-east, relative to the trends shown for 1980-2010. With the exception of ERA-Interim, the cyclonic trend anomaly in each case is associated with anomalous ascent (subsidence) to the north and east (south and west) of the circulation centre, as in the model. Although there are many differences in the details, all the plots also show easterly wind trends in equatorial winds over the western Pacific Ocean, and westerly wind trends over the eastern Indian Ocean, suggesting a strengthening of the Walker circulation over the time period. A trend of increasing equatorial westerly winds over the Indian Ocean during 1961-2000 in data from the ECMWF 40 Year Reanalysis (ERA 40) was noted by Trenary and Han (2008) and Han et al. (2010). However, Tokinaga et al. (2012) found evidence for a weakening trend during 1950-2008, using bias-corrected ship-based observations, so this is uncertain. Another aspect of Fig. 19 is that the trend magnitudes in the reanalyses are generally larger than those in Fig. 17, reflecting the fact that the modelled trends are averaged over 10 ensemble members.

It is important to note that this comparison of reanalysis data with HIST minus NO_AA is not a "clean" comparison, because HIST minus NO_AA is not an attempt to simulate the response to "all forcings". Ideally, we would compare the reanalyses with the HIST ensemble, but HIST does not capture the observed rainfall increase. The value of the comparison is that it identifies the cyclonic circulation trend in reanalyses as a likely contributor to the observed rainfall trend over NWA. The cyclonic (anticyclonic) circulation trends off the coast of NWA in HIST minus NO_AA (GHGAS) also suggest that the model shows some dynamic consistency with the real climate system in the mechanism by which it simulates trends of increasing or decreasing rainfall over NWA, even though it cannot capture the observed trend in response to "all forcings". Since the cyclonic circulation trend off the coast of NWA appears to be the key process associated with the NWA rainfall increase (both in observations and in HIST minus NO_AA), we discuss possible underlying mechanisms in the next subsection.

\subsection{What is the cause of the circulation trends?}

How do increasing GHGs induce an anticyclonic circulation trend off the coast of NWA in the model, and how do anthropogenic aerosols oppose this effect? The mechanism could involve changes in the Walker circulation or the local Hadley circulation. Either of these effects could be primarily atmospheric or involve oceanic changes. The latter could include air-sea interactions or changes in oceanic heat transports (which in turn affect SSTs). Here we consider these different possibilities. Bearing in mind that the system includes multiple feedbacks, the following discussion does not attempt to be exhaustive. As discussed earlier in this section, an intriguing aspect is that, to first order, the aerosoland GHG-induced responses are similar but of opposite sign; this applies to changes in the Walker circulation (thought to be thermodynamically driven), the local Hadley circulation (thought to be dynamically driven) and the regional circulation changes off the coast of NWA. 
(a) ERA-Interim 1980-2010

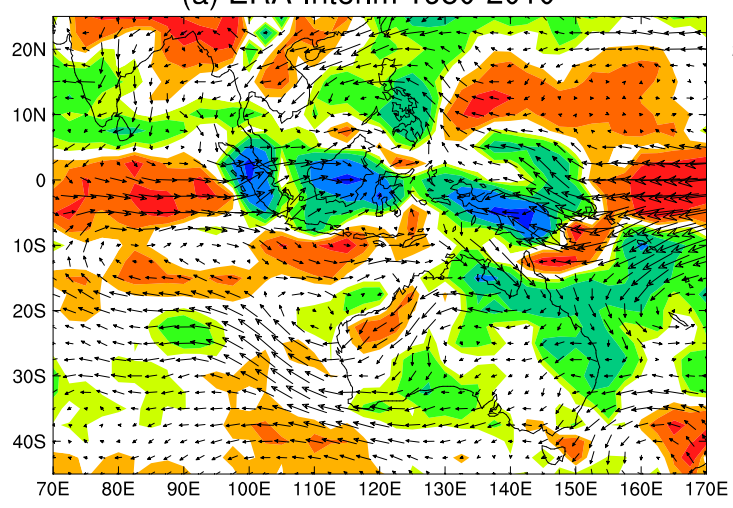

(c) NCEP1 1980-2010

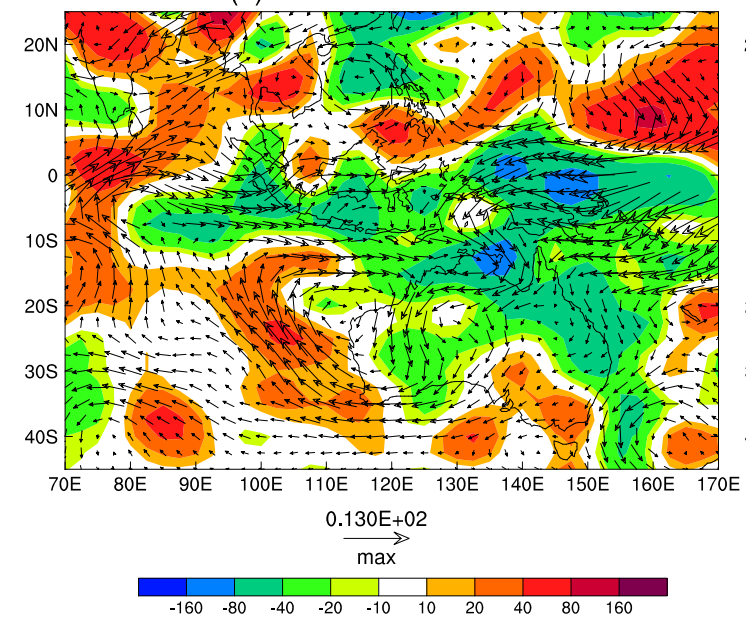

(b) NCEP2 1980-2010

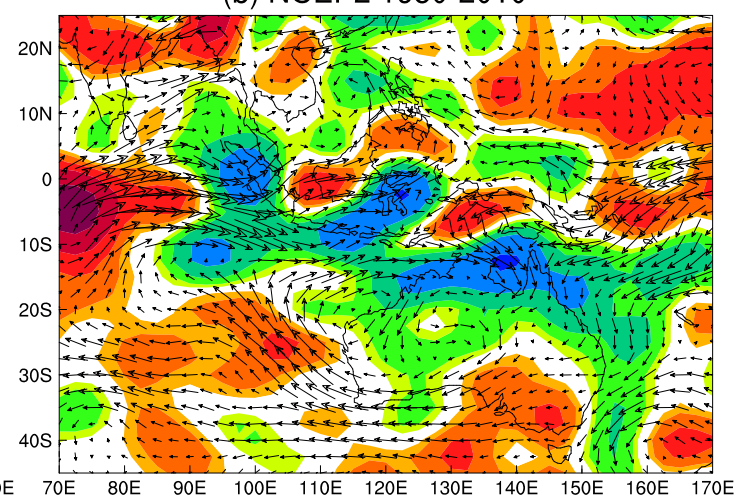

(d) NCEP1 1951-2010

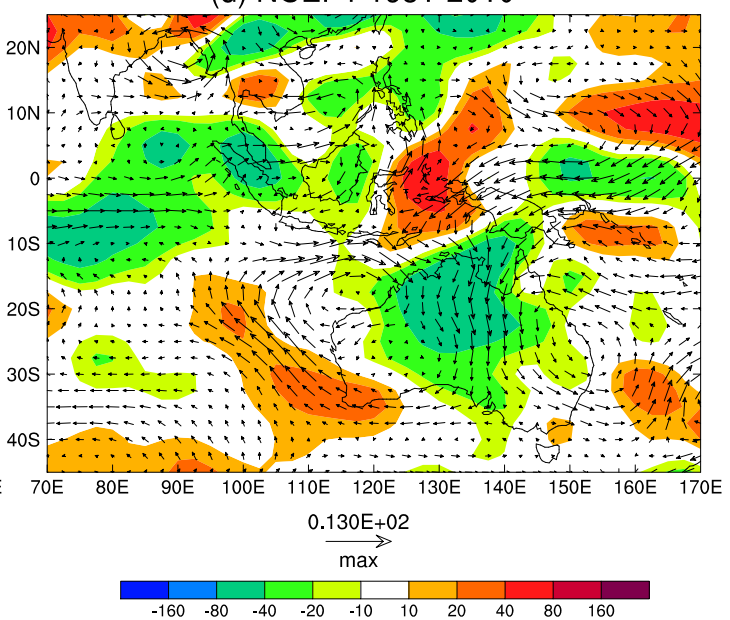

Fig. 19. Trends in $850 \mathrm{hPa}$ wind vectors $\left(\mathrm{m} \mathrm{s}^{-1}\right.$ century $\left.{ }^{-1}\right)$ and $500 \mathrm{hPa}$ vertical velocity (shading, $\mathrm{hPa} \mathrm{day}^{-1}$ century $^{-1}$ ) for DJFM from reanalyses, (a) 1979-2010 from ERA-Interim, (b) 1980-2010 from NCEP-DOE Reanalysis 2, (c) 1980-2010 from NCEP/NCAR Reanalysis 1, (d) 1951-2010 from 1980-2010 from NCEP/NCAR Reanalysis 1. The reference vector is shown at the bottom of the figure; note that scales are different from those used in Fig. 17. The ERA-Interim fields were interpolated to the $2.5^{\circ} \mathrm{NCEP}$ grid before plotting.

As we mentioned in Sect. 3.4, the anticyclonic circulation trend off the coast of NWA in GHGAS (Fig. 17a) closely resembles variations associated with ENSO (Fig. 7b), which suggests that the mechanism may be similar to that in ENSO. What is thought to be the driver of the anomalous anticyclone (cyclone) during warm (cool) ENSO events? Lau and Nath (2000) argued that it is a Gill-Matsuno Rossby wave response to a latent heating anomaly centred in the equatorial western Pacific. The Gill (1980)-Matsuno (1966) response to an equatorial heat source consists of twin cyclones that straddle the equator to the west of the heat source. However, Kajikawa et al. (2010) stated that the cyclonic circulation anomaly associated with the Australian monsoon is a Rossby wave response to the latent heating released in the monsoonal rainfall. The Rossby wave response to an off-equatorial positive heating anomaly is slightly different from the classic GillMatsuno response to a heating anomaly centred on the equator. The expected lower-tropospheric response to a tropical heat source south of the equator is a cyclonic anomaly located to its south-west (e.g. Moura and Shukla, 1981; Wang et al., 2000).

The latter suggestion is much easier to reconcile with our results: due to the equatorial cold-tongue bias in the model (Fig. 8), its ENSO-related equatorial heating anomalies are displaced too far west (similar to the rainfall trend patterns for DJFM in Fig. 10). Despite this, the model is remarkably effective at simulating the location of the ENSO-related anomalous circulation off the coast of NWA (Fig. 7). However, the Australian monsoon is locked to the northern part of the continent (in both the model and the real climate system), so the idea that the monsoonal heating is the relevant heat source is a plausible explanation for the consistency between modelled and analysed variations.

By analogy with the ENSO case, it is possible to interpret the simulated circulation trends off the NWA coast in GHGAS (HIST minus NO_AA) in terms of an eastward 
(westward) shift of the upward branch of the Walker circulation. In this view, an eastward (westward) shift of tropical convection might weaken (intensify) the latent heating over northern Australia, and this in turn affects the strength of the cyclonic circulation anomaly off the coast of NWA. We argue below that there may also be a positive feedback between the source of latent heat (the monsoon) and the circulation anomaly, so that a relatively small initial perturbation could have a substantial effect. It is difficult to see how changes in the Walker circulation could explain the observed increase of NWA rainfall, given that the consensus view suggests a weakening of the Walker circulation during the 20th century (Vecchi et al., 2006; Power and Kociuba, 2011). Put differently, the trend in NWA rainfall has persisted for decades, despite fluctuations in the Inter-decadal Pacific Oscillation (IPO; Power et al., 1999; Parker et al., 2007), which can be seen loosely as a "slow" version of ENSO. However, Meng et al. (2012) recently argued that the Walker circulation may have strengthened rather than weakened during the 20th century, and there are also conflicting views regarding trends in equatorial easterly winds over the Indian Ocean during the last few decades (Han et al., 2010; Tokinaga et al., 2012), so this is uncertain.

Another possible interpretation is that there is a Rossby wave response to off-equatorial convective heating anomalies associated with changes in the local Hadley circulation. Recall that in boreal summer (JJAS), our simulations show an aerosol-induced southward shift of equatorial rainfall between roughly $50^{\circ} \mathrm{E}$ and $150^{\circ} \mathrm{E}$, and the GHG-induced response was, to first order, similar but opposite (Fig. 10a and c). The response in DJFM more closely resembles a zonal shift associated with a change in the Walker circulation (Fig. 10b and d). However, closer examination shows that a coherent meridional shift of tropical circulation and rainfall persists until late in the calendar year, especially in HIST minus NO_AA.

Here we show how the simulated GHG- and aerosolinduced effects on the local Hadley circulation change between boreal summer and austral summer. Figure 20 shows trends in vertical pressure velocity (shaded) from GHGAS (left column) and HIST minus NO_AA (right column), zonally averaged between $70^{\circ} \mathrm{E}$ and $130^{\circ} \mathrm{E}$. In July, the response in GHGAS (HIST minus NO_AA) resembles a strengthening (weakening) of the upward branch of the local Hadley circulation over the Asian landmass, and a weakening (strengthening) of the upward branch near and south of the Equator. To some extent, the GHG- and aerosol-induced effects are similar and opposite, but there are some clear differences. In particular, the aerosol-induced effect in July is markedly stronger than the GHG-induced effect; the maximum aerosol-induced change ( $\sim 25 \mathrm{hPa}$ per day per $100 \mathrm{yr}$ ) is substantial relative to the mean upward motion (maximum $\sim 60 \mathrm{hPa}$ per day). By September, the area of weakening upward motion in HIST minus NO_AA is narrower, and centred further south (near $5^{\circ} \mathrm{N}$ ). There are areas of compensating, enhanced upward motion to the south and north. The marked difference between July and September may be related to the southward shift of the latitude of maximum insolation. The patterns in GHGAS and HIST minus NO_AA are similar but opposite in September. In November, both patterns resemble the corresponding patterns in September with a slight southward shift, and some weakening of the trends is also seen. By January, the main feature in GHGAS is an area of subsidence near and just north of the Equator, and HIST minus NO_AA shows a weaker change of opposite sign. Comparison with Fig. 17 suggests that the changes in January are more associated with the Walker circulation than the local Hadley circulation.

Figure 21 shows trends in rainfall and $850 \mathrm{hPa}$ winds from HIST minus NO_AA, for November, December, February and March. November coincides with the transition between summer and winter monsoonal winds over the Indian Ocean (e.g. Hastenrath and Polzin, 2004). In that month, (Fig. 21a) Mk3.6 shows a clear southward shift of equatorial rainfall south of the Asian continent, consistent with the circulation changes shown in Fig. 20f. Note that the pattern over the Indian Ocean also resembles a negative Indian Ocean Dipole event, with positive rainfall anomalies off the coast of Sumatra, and negative anomalies south and south-west of India. There is an elongated cyclonic circulation anomaly located to the south-west of the positive heating anomalies near Java and Sumatra, suggestive of a Rossby wave response to the heating anomaly. A similar point was made by Wang et al. (2003) to explain the location of the anomalous anticylone during the austral spring of a developing El Niño. In December, there is still some remaining evidence of a southward shift of equatorial rainfall. The cyclonic circulation is less coherent in December than in November; it has split into two smaller cells, which appear to correspond to the positive convective heating anomalies centred near Sumatra and off the north coast of Australia. In January (not shown), the cyclonic circulation feature becomes stronger and re-forms as a single, elongated cell. It is stronger again in February, and is centred further east, just off the coast of NWA. Its location appears consistent with the peak convective heating trend over northern Australia, and its elongated shape can also be explained by the extended band of increased convective heating that extends in a westerly direction from the top end of Australia.

To some extent, the GHG-induced trends in Fig. 22 resemble the inverse of the aerosol-induced trends in Fig. 21, though there are some marked differences. In November, HIST minus NO_AA (Fig. 21a) shows an unbroken band of decreasing rainfall along the equator, but in GHGAS the rainfall changes are suggestive of a shift in the Walker circulation (Fig. 22a). In November and December, the anticyclonic circulation trend in the Indian Ocean in GHGAS is better defined than the cyclonic feature in HIST minus NO_AA. However, the circulation trends in both GHGAS and HIST minus NO_AA are strong and well defined in February and March. 

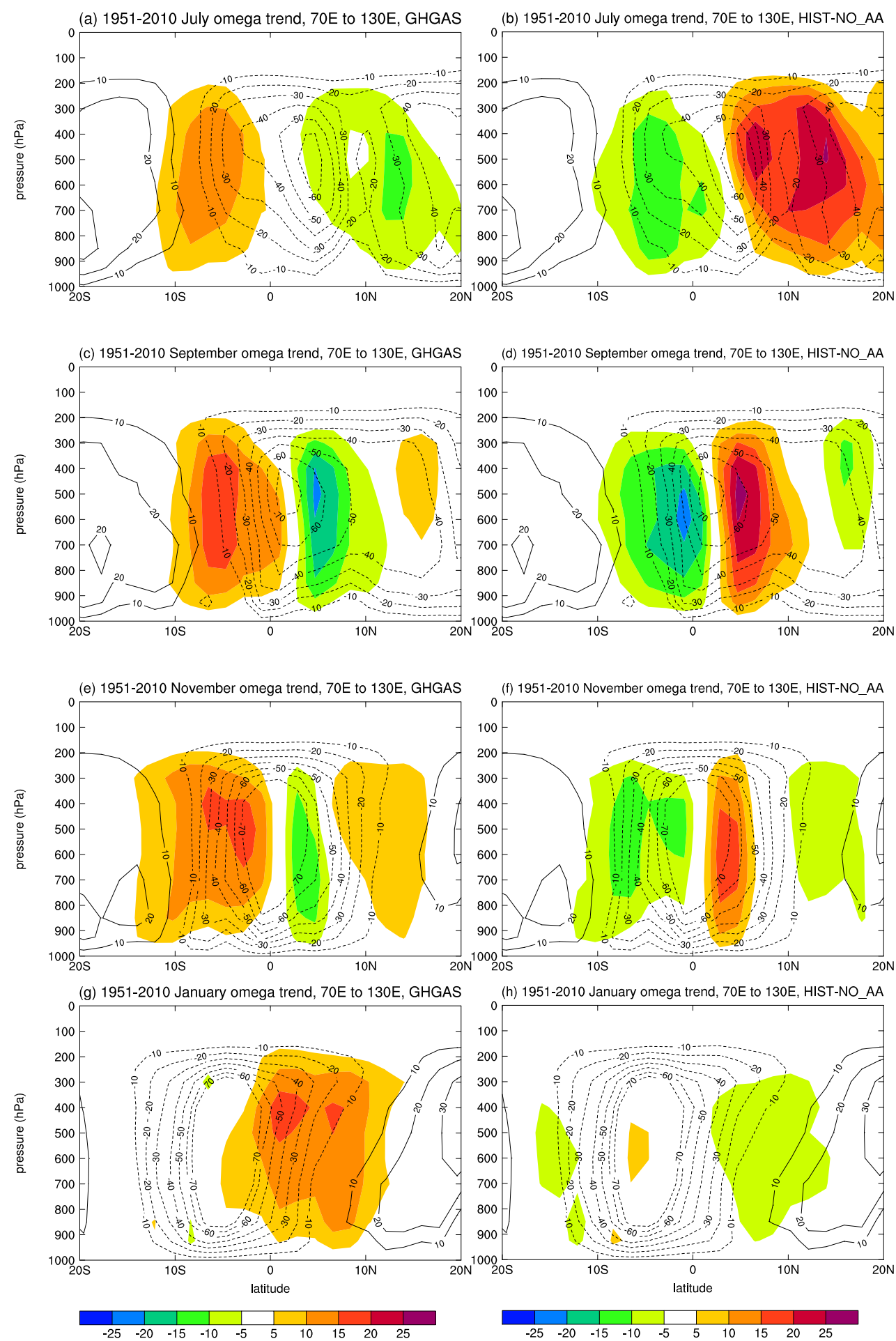

Fig. 20. 1951-2010 ensemble-mean trends of vertical pressure velocity, zonally averaged between $70^{\circ} \mathrm{E}$ to $130^{\circ} \mathrm{E}$ (shading, hPa day $^{-1}$ century $^{-1}$ ) for (a, b) July, (c, d) September, $(\mathbf{e}, \mathbf{f})$ November and $(\mathbf{g}, \mathbf{h})$ January, from GHGAS (left column) and HIST minus NO_AA (right column). For each month, the black contours show the mean vertical velocity field (averaged over 1970-1989 from the HIST ensemble); negative contours (denoting upward motion) are dashed. Contour interval is $10 \mathrm{hPa} \mathrm{day}^{-1}$, with the zero contour omitted. 
There is a circular "chicken and egg" argument that relates the circulation anomaly to the monsoonal heat source: in HIST minus NO_AA, moisture convergence (Fig. 18) due to a stronger cyclonic circulation enhances the monsoonal convective heat source, which in turn enhances the circulation via the Rossby wave response. Also, in March, which generally corresponds to the retreat of the Australian monsoon (e.g. Kajikawa et al., 2010), the aerosol-induced effect appears as an even stronger enhancement of the monsoonal north-westerly winds compared to February, and the enhanced north-westerlies extend even further westward towards the central Indian Ocean. The converse applies in GHGAS. These points suggest that the process we described may entail a positive feedback, in which case a relatively small initial perturbation could lead to a substantial change in NWA rainfall.

Do SSTs have a substantial role in forcing the circulation trends off the coast of NWA in the model? It is noticeable that the south-eastern tropical Indian Ocean is an area where $T_{\text {rel }}$ increases (decreases) quite strongly in HIST minus NO_AA (GHGAS) in Fig. 15. It is possible that changes in the Indonesian Throughflow (ITF) contribute to these trends. The ITF is recognised as an important heat source for the southeastern Indian Ocean (Hirst and Godfrey, 1993; Schneider, 1998), and it tends to weaken in response to weaker easterly winds in the equatorial western Pacific (Meyers, 1996; Alory et al., 2007). Simulated changes in the ITF transport during 1951-2010 show an increase in HIST minus NO_AA and a decrease in GHGAS, so they are in the right sense to contribute to the $T_{\text {rel }}$ trends. However, the changes (not shown) were of the order of $10 \%$, and it is unclear whether they would have a substantial effect. Westerly wind anomalies in the eastern equatorial Indian Ocean in HIST minus NO_AA may also generate downwelling Kelvin waves, which will tend to warm the eastern Indian Ocean by deepening the thermocline (e.g. Rao and Yamagata, 2004). A rigorous assessment would require a detailed analysis of the oceanic heat budget, which we intend to address in a separate study.

It is interesting that $T_{\text {rel }}$ trends in GHGAS and HIST minus NO_AA (Fig. 15b and d) have maximum magnitudes near $20^{\circ} \mathrm{S}, 110^{\circ} \mathrm{E}$, nearly collocated with the circulation centres (Fig. 17). The locations of the cyclonic or anticyclonic circulation centres were also similar in analysed trends (Fig. 19) and ENSO-related inter-annual variations (Fig. 7). Positive SST anomalies in the tropics tend to induce convection, suggesting that these SST extrema contribute to local anomalies in convection and circulation. There is also evidence that the atmosphere strongly forces SSTs around northern Australia in summer (Hendon et al., 2012); this suggests that the spatial structure of the $T_{\text {rel }}$ trends may, in part, reflect the effect of the atmosphere on the ocean, e.g. via changes in surface wind speed.

Do SST observations shed any light on this matter? Two globally complete, historical SST analyses are the $1^{\circ}$ HadISST 1.1 data set and the $2^{\circ}$ NOAA Extended Re- constructed Sea Surface Temperature analysis (ERSST.v3b). ERSST.v3b is as described by Smith et al. (2008), except that satellite SST retrievals are not used in ERSST.v3b. HadISST and ERSST.v3b use different statistical procedures to smooth the data and fill in missing values; a further difference between them is that HadISST includes information from satellite retrievals.

Figure 23 shows SST trends (relative to the low-latitude mean trend) from HadISST and ERSST.v3b for 1951-2010. There is less agreement over the south-eastern Indian Ocean than over much of the Pacific Ocean. There is an area along the NWA coastline where both data sets show a negative SST trend, which could be consistent with increasing monsoonal north-westerlies. As noted by Deser et al. (2010) accurate calculation of SST trends is hampered by sparse sampling and inhomogeneous measurement practices. Further, the tropical south-eastern Indian Ocean is a relatively datasparse region; see the SST coverage maps at http://icoads. noaa.gov/r2.5sst.html, which extend Fig. 3 of Woodruff et al. (2011) to a range of different time periods. Thus the analysed SST trends in this region are not sufficiently robust to resolve the relatively modest SST gradients seen off the coast of NWA in the model.

Idealised simulations are potentially a useful way to tease apart the possible mechanisms. For example, latent heating anomalies could be prescribed in the region of the Australian monsoon, perhaps in conjunction with prescribed SSTs or a mixed-layer ocean model. Similarly, SST anomalies could be prescribed off the coast of NWA; in this case, SSTs elsewhere could be prescribed, or calculated using a mixed-layer ocean model (e.g. Lau and Nath, 2000).

\subsection{Further discussion}

Our results suggest that a lower-tropospheric cyclonic circulation trend off the coast of NWA is the key process that underlies the NWA rainfall increase. A cyclonic circulation anomaly off the coast of NWA was also identified by Shi et al. (2008) and Lin and Li (2012) in studies of the NWA rainfall trend. Shi et al. (2008) used empirical orthogonal functions to determine two modes of interannual variability of Australian summer rainfall. The first of these modes was associated with a cyclonic circulation anomaly off the coast of NWA, and they argued that variations of this mode were instigated by a pattern of enhanced SST gradients toward the Australian coast in the Indian Ocean. However, as shown in Fig. 23, observed SSTs do not show evidence of such a trend, so this remains an open question. Lin and $\mathrm{Li}$ (2012) linked the observed NWA rainfall increase (and associated circulation anomalies) to a Rossby wave train that travels eastward from the tropical Atlantic Ocean, embedded in the westerly jet waveguide of the Southern Hemisphere. They thus suggested that the observed rainfall increase in NWA may be driven, at least in part, by enhanced ascent 
(a) Rainfall and $850 \mathrm{hPa}$ wind trends, November, HIST minus NO_AA

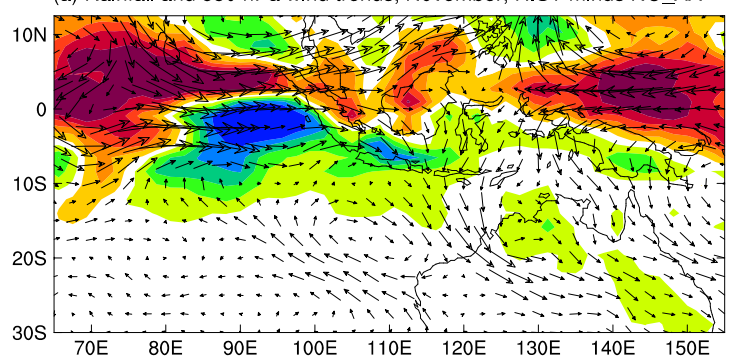

(c) Rainfall and $850 \mathrm{hPa}$ wind trends, February, HIST minus NO_AA

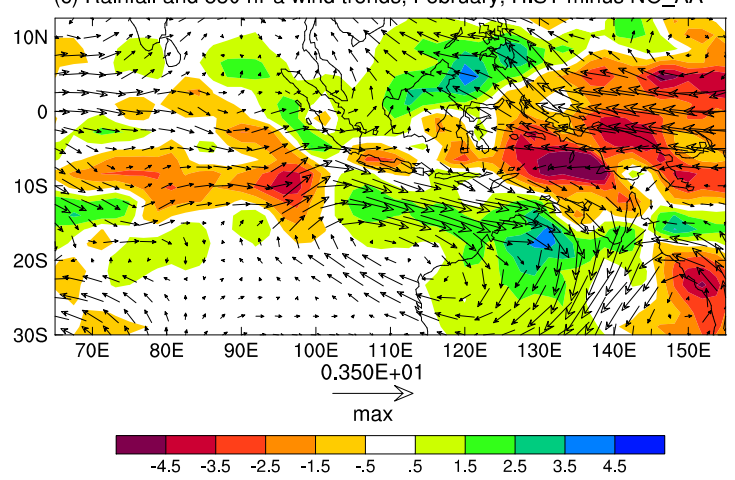

(b) Rainfall and $850 \mathrm{hPa}$ wind trends, December, HIST minus NO_AA

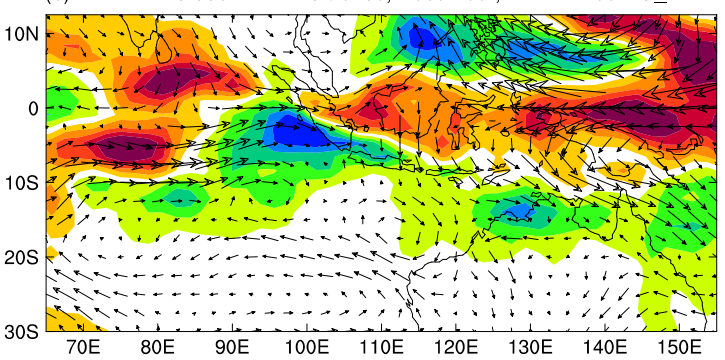

(d) Rainfall and $850 \mathrm{hPa}$ wind trends, March, HIST minus NO AA

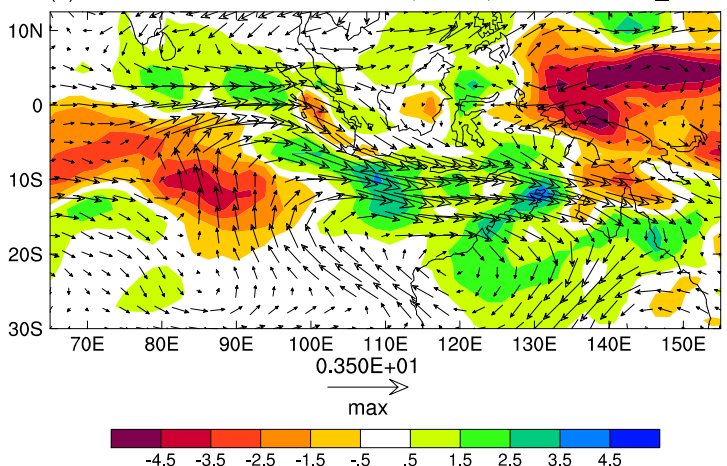

Fig. 21. 1951-2010 HIST minus NO_AA ensemble-mean trends of rainfall (shading, mm day ${ }^{-1}$ century $^{-1}$ ) and $850 \mathrm{hPa}$ wind (vectors, $\mathrm{m} \mathrm{s}^{-1}$ century $^{-1}$ ), for (a) November, (b) December, (c) February and (d) March.

(a) Rainfall and $850 \mathrm{hPa}$ wind trends, November, GHGAS

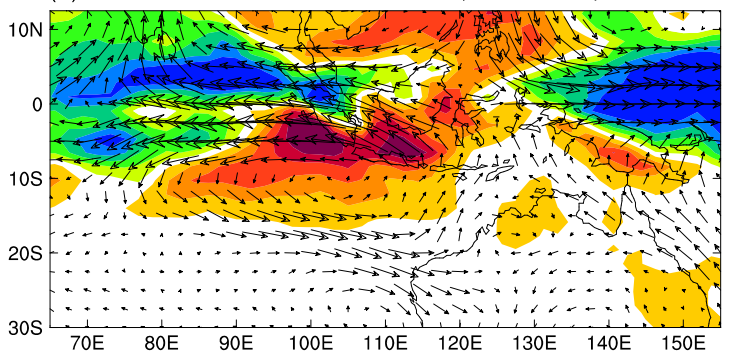

(c) Rainfall and $850 \mathrm{hPa}$ wind trends, February, GHGAS

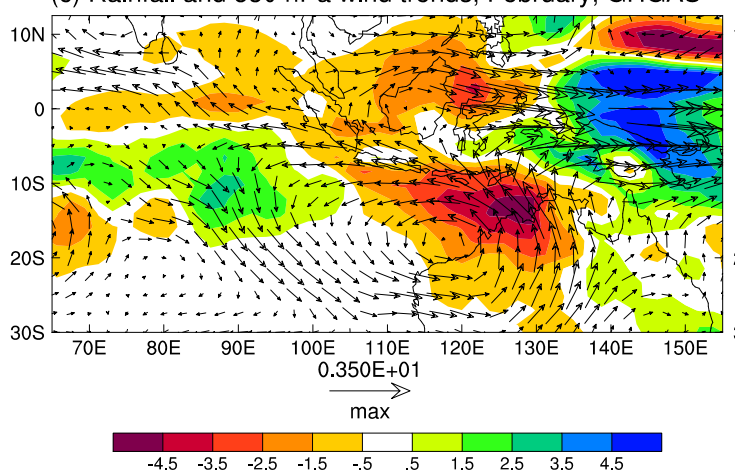

(b) Rainfall and $850 \mathrm{hPa}$ wind trends, December, GHGAS

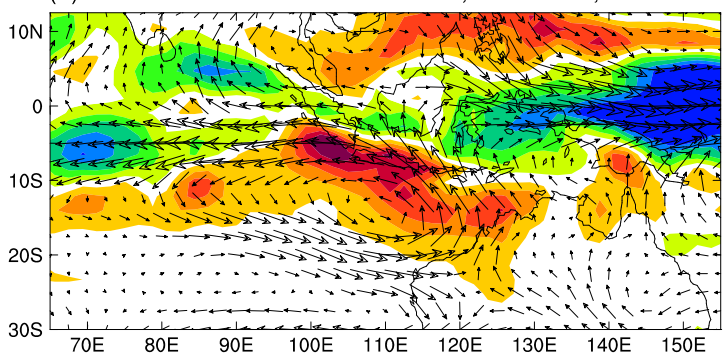

(d) Rainfall and $850 \mathrm{hPa}$ wind trends, March, GHGAS

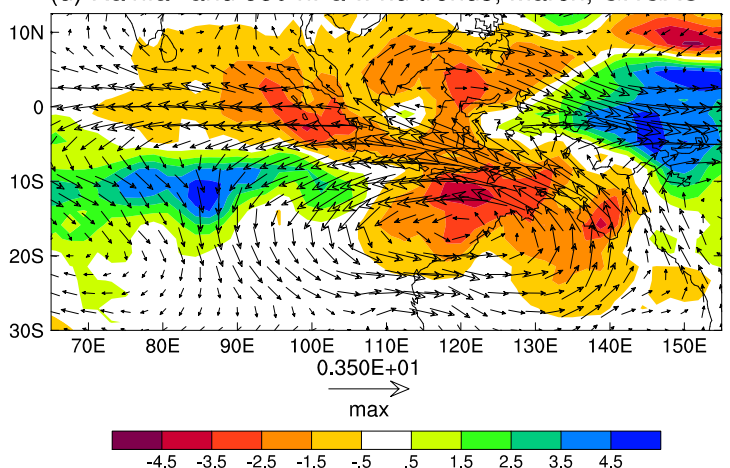

Fig. 22. 1951-2010 GHGAS ensemble-mean trends of rainfall (shading, mm day ${ }^{-1}$ century $^{-1}$ ) and 850 hPa wind (vectors, $\mathrm{m} \mathrm{s}^{-1}$ century $^{-1}$ ), for (a) November, (b) December, (c) February and (d) March. 
(a) HadISST 1951-2010 DJFM SST trend relative to tropical mean

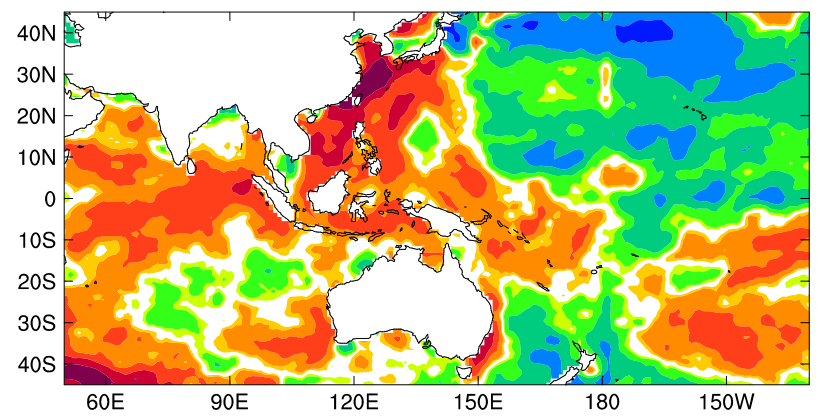

(b) ERSST.v3b 1951-2010 DJFM SST trend relative to tropical mean

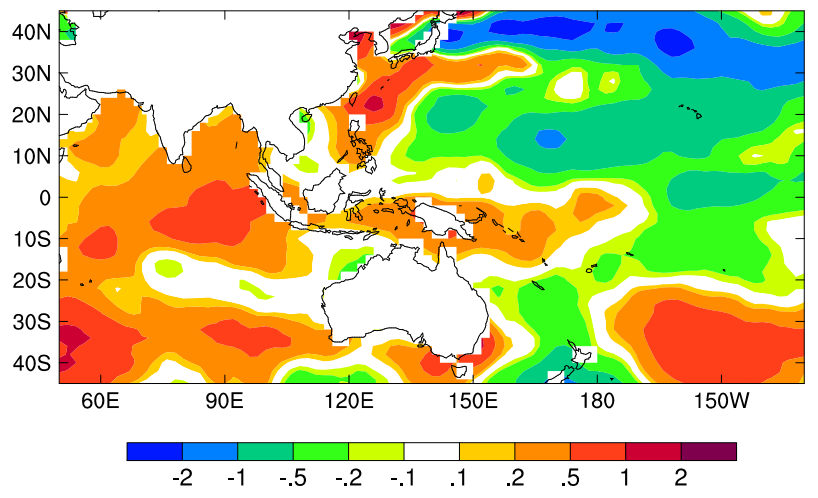

Fig. 23. Analysed DJFM SST trends for 1951-2010 with the lowlatitude $\left(30^{\circ} \mathrm{S}-30^{\circ} \mathrm{N}\right)$ mean trend subtracted $\left(\mathrm{K}\right.$ century $\left.^{-1}\right)$, (a) HadISST, (b) ERSST.v3b.

induced by increasing SST in the tropical Atlantic. This is an interesting hypothesis that merits further research.

An important way forward will be to compare the responses of other CMIP5 models; it is hoped that this will include a substantial set of runs that isolate the anthropogenic aerosol forcing (Boucher et al., 2011). The NWA rainfall response to increasing GHGs (and presumably anthropogenic aerosols) is model-dependent (Watterson, 2012; Cai et al., 2011). This might reflect the fact that NWA is on the fringe of a region with very heavy rainfall, so its response under climate change is likely to be a delicate balance between competing dynamic and thermodynamic effects (Chou and Neelin, 2004; Held and Soden, 2006). Exploring the phase space of possibilities in two dimensions (forcing and models) is likely to yield more insights than can be gained from a single model.

CSIRO-Mk3.6 projects strongly decreasing rainfall over much of Australia in the 21st century (in the annual mean as well as DJFM), which is an alarming result for a country that has limited water resources. Watterson (2012) compared 21st century simulations from 23 CMIP3 GCMs and found that projected Australian rainfall changes correlated strongly with changes in a "Pacific-Indian Dipole index", similar to the equatorial SST trend pattern seen in our runs dominated by GHG forcing; in other words, models that project a rela- tively warm central-western Pacific and a relatively cool eastern Indian Ocean tend to project a stronger decrease of rainfall over Australia, including NWA. A majority of models project a decrease of rainfall over NWA, but a sizeable minority project an increase. Based on this categorisation, the predecessor of CSIRO-Mk3.6 (Mk3.5) was among the models with the largest projected rainfall decreases, and Mk3.6 behaves similarly. Further, Cai et al. (2011) showed that GCMs with stronger Indian Ocean Dipole (IOD) variability tend to produce a slower eastern Indian Ocean warming rate and greater future rainfall changes in IOD-affected regions, including Australia. Using the method from Cai et al. (2011), Mk3.6 has an IOD amplitude of $0.40^{\circ} \mathrm{C}$, more than twice the observed value. These results provide some insight into why our model simulates a relatively strong drying trend over Australia in RCP4.5.

\section{Summary and conclusions}

As a part of CMIP5, we used the CSIRO-Mk3.6 GCM to perform 10-member ensembles of AOGCM historical (18502010) simulations driven by different combinations of forcing agents, and compared these with 21 st century projections based on RCP4.5. We looked at changes in rainfall and circulation in the Indo-Pacific region in DJFM, with a primary focus on the observed rainfall increase over north-western Australia (NWA) during 1951-2010, and whether this increase can be attributed to anthropogenic forcing. We paid particular attention to an historical ensemble forced solely by increasing long-lived GHGs (GHGAS), and aerosol-induced effects diagnosed as the difference of HIST minus NO_AA, where HIST was an ensemble with "all forcings", and NO_AA was the same as HIST, except that anthropogenic aerosol forcing was suppressed.

There was a statistically significant increase (decrease) of summer rainfall over north-western and central Australia during 1951-2010 in HIST minus NO_AA (GHGAS), whereas HIST gave relatively small and insignificant rainfall increases. RCP4.5 gave a rainfall decrease with a similar pattern to that in GHGAS, but it was larger in magnitude, reflecting the stronger long-lived GHG forcing in the 21st century. Comparison of these experiments explained why the strong projected rainfall decrease in RCP4.5 was not obtained in HIST: the GHG-induced rainfall decrease was "masked" by changes in anthropogenic aerosols, and (to a lesser extent) ozone.

The model was unable to capture the large $(2.72 \mathrm{~mm}$ per day per century) observed 1951-2010 rainfall increase over NWA in a series of 440 unforced $60-\mathrm{yr}$ trends from the pre-industrial control run. Together with the finding that the model's decadal variability appeared to be realistic, this suggested that the observed rainfall increase includes a forced component. However, the model was also unable to simulate the observed rainfall increase in HIST, even in a single 
ensemble member. Our suggested answers to this apparent paradox were (1) that because the simulated response to each forcing contains errors, the response to "all forcings" is also inaccurate, and (2) it is difficult to reliably estimate the true decadal variability of NWA rainfall, due to limitations of the observational record, and the fact that this record may include a forced trend.

When we paired the individual runs from HIST with their corresponding runs from NO_AA, two of 10 realisations of HIST minus NO_AA produced 1951-2010 NWA rainfall trends that were larger than the observed value. In other words, the aerosol-induced effect (in isolation) plus natural variability could explain the observed rainfall trend in our model. However, given that the real climate system includes forcing from both aerosols and GHGs, this did not amount to an attribution of the NWA rainfall trend. With this caveat in mind, we sought insights into possible causes of the NWA rainfall trend by investigating circulation changes in the model and in observations.

The aerosol-induced circulation response over the IndoPacific region in DJFM resembled a westward shift and strengthening of the upward branch of the Walker circulation (essentially the inverse of the GHG-induced response). The aerosol-induced response was similar to a La Niña-like pattern in the tropics, consistent with the postulated thermodynamic effect whereby anthropogenic aerosols oppose a GHG-induced weakening of the Walker circulation. We attributed the lack of a clear meridional response in DJFM to the fact that there is insufficient latent heating across southern Asia to provoke a substantial change in the local Hadley circulation (in response to GHGs or anthropogenic aerosols). The response was quite different in boreal summer, when aerosols caused a southward shift of equatorial rainfall, consistent with the idea that anthropogenic aerosols have suppressed Asian monsoonal rainfall, and caused a southward shift of the upward branch of the local Hadley circulation; to first order, the GHG-induced effect was again similar but of opposite sign to the aerosol-induced effect. We also noted that (1) the underlying mechanisms are somewhat different in boreal summer, in the sense that anthropogenic aerosols exert strong regional forcing over Asia, whereas the response to increasing GHGs reflects rapid transient warming of the Asian continent compared to the surrounding oceans, and (2) the regional aerosol-induced response was not exactly the inverse of the GHG-induced response; in particular, the dynamic response whereby aerosols alter the local Hadley circulation in boreal summer was stronger than the corresponding effect for GHGs, whereas the thermodynamic effect on the Walker circulation in DJFM was stronger for GHGs than for aerosols.

A fundamental aspect of the mechanism in the model was a cyclonic low-level circulation trend centred off the coast of NWA in HIST minus NO_AA, and a similar response of opposite sign in GHGAS. The aerosol-induced cyclonic circulation trend induced moisture convergence and upward motion over NWA. Circulation trends from reanalyses showed cyclonic circulation trends off the coast of NWA with a marked similarity to the aerosol-induced trend in the model. We noted that the comparison of reanalysis data with HIST minus NO_AA was not a "clean" comparison, because HIST minus NO_AA was not an attempt to simulate the response to "all forcings". However, this exercise identified the cyclonic circulation trend in reanalyses as a likely contributor to the observed rainfall trend over NWA. The cyclonic (anticyclonic) circulation trends off the coast of NWA in HIST minus NO_AA (GHGAS) also suggested that the model shows some dynamic consistency with the real climate system in the mechanism by which it simulated trends of increasing or decreasing rainfall over NWA, even though it was unable to capture the observed trend in response to all forcings.

We considered some mechanisms by which increasing GHGs could induce an anticyclonic circulation trend off the coast of NWA in the model, whereas anthropogenic aerosols have the opposite effect. Possible mechanisms could involve changes in the Walker circulation or the local Hadley circulation, and either of these effects could be primarily atmospheric or involve oceanic changes. The anticyclonic (cyclonic) circulation trend off the coast of NWA in GHGAS (HIST minus NO_AA) closely resembled variations associated with ENSO, both in the model and reanalyses; this suggested that the mechanism may be similar to ENSO, involving changes in the Walker circulation. A plausible atmospheric mechanism linked to the Walker circulation was that the circulation anomalies are a Rossby wave response to off-equatorial heating anomalies associated with Australian monsoonal rainfall. We also discussed the possible role of changes in oceanic heat transport by the Indonesian Throughflow in response to changes in the Walker circulation; these may have contributed to relative warming (cooling) of SSTs in the south-east Indian Ocean in HIST minus NO_AA (GHGAS). However, as an explanation for the observed increase of NWA rainfall, these mechanisms were difficult to reconcile with the consensus view that suggests a weakening of the Walker circulation during the 20th century.

In considering possible explanations involving changes in the Hadley circulation, we found that a coherent meridional shift of tropical circulation and rainfall persists until late in the calendar year, especially in HIST minus NO_AA. In November, the transitional month between the summer and winter monsoons, the model's aerosol-induced response over the Indian Ocean still resembled that in boreal summer (namely, a southward shift of equatorial rainfall and the local Hadley circulation). To some extent GHGAS showed a similar but opposite response, but it also had the character of a shift in the Walker circulation. In November and December, GHGAS (HIST minus NO_AA) showed an anticyclonic (cyclonic) circulation trend in the south-eastern Indian Ocean, with a location consistent with a Rossby wave response to convective heating anomalies south of the Equator. In both ensembles, the feature moved eastward towards NWA during 
austral summer, and by February its location was consistent with a Rossby wave response to monsoonal latent heating.

We argued that there may be a "chicken and egg" relationship between the circulation anomaly and the monsoonal heat source: in HIST minus NO_AA, moisture convergence due to a stronger cyclonic circulation enhanced the monsoonal convective heat source, which in turn enhanced the circulation via the Rossby wave response. Conversely, negative heating anomalies enhanced the anticyclonic circulation in $\mathrm{GH}-$ GAS. This suggested the possibility of a positive feedback, in which case a relatively small initial perturbation could lead to a substantial change in NWA rainfall. This could equally apply to perturbations associated with changes in the Walker circulation, or to perturbations initiated by forcing agents other than aerosols. Further work is needed to establish the veracity of these mechanisms, both in the model and in observations.

There are other caveats regarding our results. Possibly the most substantial is the large uncertainty in the magnitude and spatial pattern of anthropogenic aerosol forcing. Mk3.6 has a lower oceanic heat uptake over recent decades than observations; this may indicate that our anthropogenic aerosol forcing of $-1.4 \mathrm{~W} \mathrm{~m}^{-2}$ is too large in magnitude (J. Church, personal communication, 2011). This is also suggested by the model's underestimate of global-mean warming in the late 20th century, given that the equilibrium climate sensitivity of CSIRO-Mk3.6 is somewhat higher than the average of CMIP5 models (Andrews et al., 2012). Further, as discussed in Sect. 3.6, the response of NWA rainfall to increasing GHGs differs among GCMs, and a substantial minority projects an increase instead of a decrease. By implication, even if the magnitude and spatial pattern of aerosol forcing were known perfectly, the response of NWA rainfall would also differ among models. An interesting question is whether forcing due to anthropogenic aerosols and increasing GHGs in the CMIP5 models generally have opposing effects on NWA rainfall, or whether even this is modeldependent. The effect of stratospheric ozone depletion, as discussed in Sect. 3.2, is another promising avenue for further research.

In summary, CSIRO-Mk3.6 suggests that anthropogenic aerosols may have masked greenhouse gas-induced changes in rainfall over NWA and in circulation over the wider Indo-Pacific region: simulated trends in RCP4.5 resemble a stronger version of those in GHGAS, and are very different from those in HIST. Future trends may thus be very different from trends observed over the last few decades. More generally, we argue that GCM simulations driven by individual forcing agents, or combinations thereof, are a valuable tool that can help to reduce uncertainty in future climate projections. Our results are limited by the fact that they rely on only one model. Having access to ensembles of such runs that use a range of GCMs, preferably within the CMIP5 framework, would potentially be very powerful.

\section{Supplementary material related to this article is available online at: http://www.atmos-chem-phys.net/12/ 6377/2012/acp-12-6377-2012-supplement.pdf.}

Acknowledgements. The authors thank Alena Chrastansky, Jing-Jia Luo and two anonymous reviewers for their constructive comments on the manuscript, Ming Feng and Catia Domingues for helpful discussions, and Arnold Sullivan for assistance with calculation of the IOD amplitude. The Queensland Government Department of Environment and Resource Management provided the high performance computing facilities for the CSIRO-Mk3.6 simulations. The National Computational Infrastructure National Facility in Canberra provided storage and processing resources for the post-processing, and hardware for hosting the Mk3.6 CMIP5 data via the Earth System Grid. NCEP Reanalysis data were provided by the NOAA/OAR/ESRL PSD, Boulder, Colorado, USA, from their web site at http://www.esrl.noaa.gov/psd/. ECMWF ERA-Interim data used in this study were obtained from the ECMWF data server. This work was partly supported by the Australian Climate Change Science Program and the Indian Ocean Climate Initiative.

Edited by: J. Quaas

\section{References}

Ackerley, D., Booth, B. B. B., Knight, S. H. E., Highwood, E. J., Frame, D. J., Allen, M. R., and Rowell, D. P.: Sensitivity of 20th Century Sahel Rainfall to Sulfate Aerosol and $\mathrm{CO}_{2}$ Forcing, J. Climate, 24, 4999-5014, doi:10.1175/JCLI-D-11-00019.1, 2011.

Alexander, M. A., Bladé, I., Newman, M., Lanzante, J. R., Lau, N. C., and Scott, J. D.: The atmospheric bridge: The influence of ENSO teleconnections on air-sea interaction over the global oceans, J. Climate, 15, 2205-2231, 2002.

Alory, G., Wijffels, S., and Meyers, G.: Observed temperature trends in the Indian Ocean over 1960-1999 and associated mechanisms, Geophys. Res. Lett., 34, L02606, doi:10.1029/2006GL028044, 2007.

Andrews, T., Forster, P. M., Boucher, O., Bellouin, N., and Jones, A.: Precipitation, radiative forcing and global temperature change, Geophys. Res. Lett., 37, L14701, doi:10.1029/2010GL043991, 2010.

Andrews, T., Gregory, J. M., Webb, M. J., and Taylor, K. E.: Precipitation, radiative forcing and global temperature change, Geophys. Res. Lett., 37, L09712, doi:10.1029/2012GL051607, 2012.

Arblaster, J. M. and Meehl, G. A.: Contributions of External Forcings to Southern Annular Mode Trends, J. Climate, 19, 28962905, 2006.

Berry, G., Reeder, M. J., and Jakob, C.: Physical mechanisms regulating summertime rainfall over north-western Australia, J. Climate, 24, 3705-3717, 2011.

Boer, G. J., Flato, G., and Ramsden, D.: A transient climate change simulation with greenhouse gas and aerosol forcing: projected climate to the twenty-first century, Climate Dyn., 16, 427-450, doi:10.1007/s003820050338, 2000.

Bollasina, M. A., Ming, Y., and Ramaswamy, V.: Anthropogenic aerosols and the weakening of the South Asian summer mon- 
soon, Science, 334, 502-505, doi:10.1126/science.1204994, 2011.

Boucher, O., Collier, M., Dufresne, J.-L., Forster, P., Haywood, J., Jeffrey, S., Jones, A., Lohmann, U., Rasch, P., Rotstayn, L., Stevens, B., Taylor, K., and von Salzen, K.: Climate response to aerosol forcings in CMIP5, CLIVAR Exchanges, 56, 2527, http://www.clivar.org/publications/exchanges/Exchanges_56. pdf, 2011.

Brohan, P., Kennedy, J. J., Harris, I., Tett, S. F. B., and Jones, P. D.: Uncertainty estimates in regional and global observed temperature changes: A new data set from 1850, J. Geophys. Res., 111, D12106, doi:10.1029/2005JD006548, 2006.

Cai, W., Sullivan, A., Cowan, T., Ribbe, J., and Shi, G.: Simulation of the Indian Ocean Dipole: A relevant criterion for selecting models for climate projections, Geophys. Res. Lett., 38, L3704, doi:10.1029/2010GL046242, 2011.

Cai, W., Cowan, T., Sullivan, A., Ribbe, J., and Shi, G.: Are anthropogenic aerosols responsible for the northwest Australia summer rainfall increase? A CMIP3 perspective and implications, J. Climate, 24, 2556-2564, doi:10.1175/2010JCLI3832.1, 2011.

Chen, J., Carlson, B. E., and Del Genio, A. D.: Evidence for Strengthening of the Tropical General Circulation in the 1990s, Science, 295, 838-841, doi:10.1126/science.1065835, 2002.

Chou, C. and Neelin, J. D.: Mechanisms of Global Warming Impacts on Regional Tropical Precipitation, J. Climate, 17, 26882701, 2004.

Cionni, I., Eyring, V., Lamarque, J. F., Randel, W. J., Stevenson, D. S., Wu, F., Bodeker, G. E., Shepherd, T. G., Shindell, D. T., and Waugh, D. W.: Ozone database in support of CMIP5 simulations: results and corresponding radiative forcing, Atmos. Chem. Phys., 11, 11267-11292, doi:10.5194/acp-11-11267-2011, 2011.

Clarke, L., Edmonds, J., Jacoby, H., Pitcher, H., Reilly, J., and Richels, R.: Scenarios of Greenhouse Gas Emissions and Atmospheric Concentrations, Sub-report 2.1A of Synthesis and Assessment Product 2.1, Department of Energy, Washington, DC, USA, 154 pp., 2007.

Dee, D. P., Uppala, S. M., Simmons, A. J., Berrisford, P., Poli, P., Kobayashi, S., Andrae, U., Balmaseda, M. A., Balsamo, G., Bauer, P., Bechtold, P., Beljaars, A. C. M., van de Berg, L., Bidlot, J., Bormann, N., Delsol, C., Dragani, R., Fuentes, M., Geer, A. J., Haimberger, L., Healy, S. B., Hersbach, H., Holm, E. V., Isaksen, L., Kallberg, P., Koehler, M., Matricardi, M., McNally, A. P., Monge-Sanz, B. M., Morcrette, J. J., Park, B. K., Peubey, C., de Rosnay, P., Tavolato, C., Thepaut, J. N., and Vitart, F.: The ERA-Interim reanalysis: Configuration and performance of the data assimilation system, Q. J. Roy. Meteorol. Soc., 137, 553597, doi:10.1002/qj.828, 2011.

Deser, C., Phillips, A. S., and Alexander, M. A.: Twentieth century tropical sea surface temperature trends revisited, Geophys. Res. Lett., 37, L10701, doi:10.1029/2010GL043321, 2010.

Deser, C., Phillips, A., Bourdette, V., and Teng, H.: Uncertainty in climate change projections: the role of internal variability, Climate Dyn., 38, 527-546, doi:10.1007/s00382-010-0977-x, 2012.

DiNezio, P. N., Clement, A. C., Vecchi, G. A., Soden, B. J., Kirtman, B. P., and Lee, S.: Climate Response of the Equatorial Pacific to Global Warming, J. Climate, 22, 4873-4892, doi:10.1175/2009JCLI2982.1, 2009.

Feichter, J., Roeckner, E., Lohmann, U., and Liepert, B.: Nonlinear aspects of the climate response to greenhouse gas and aerosol forcing, J. Climate, 17, 2384-2398, 2004.

Feng, M., Biastoch, A., Böning, C., Caputi, N., and Meyers, G.: Seasonal and interannual variations of upper ocean heat balance off the west coast of Australia, J. Geophys. Res., 113, C12025, doi:10.1029/2008JC004908, 2008.

Forster, P., Ramaswamy, V., Artaxo, P., Berntsen, T., Betts, R., Fahey, D., Haywood, J., Lean, J., Lowe, D., Myhre, G., Nganga, J., Prinn, R., Raga, G., Schulz, M., and Dorland, R. V.: Changes in Atmospheric Constituents and in Radiative Forcing, in: Climate Change 2007: The Physical Science Basis. Contribution of Working Group I to the Fourth Assessment Report of the Intergovernmental Panel on Climate Change, edited by: Solomon, S., Qin, D., Manning, M., Chen, Z., Marquis, M., Averyt, K. B., Tignor, M., and Miller, H. L., Cambridge University Press, Cambridge, United Kingdom and New York, NY, USA, 2007.

Gill, A. E.: Some simple solutions for heat-induced tropical circulation, Q. J. R. Meteorol. Soc., 106, 447-462, doi:10.1256/smsqj.44904, 1980.

Gordon, H. B., Rotstayn, L. D., McGregor, J. L., Dix, M. R., Kowalczyk, E. A., O'Farrell, S. P., Waterman, L. J., Hirst, A. C., Wilson, S. G., Collier, M. A., Watterson, I. G., and Elliott, T. I.: The CSIRO Mk3 Climate System Model, Technical Paper No. 60, CSIRO Atmospheric Research, Aspendale, Vic., Australia, 134 pp., available online at: http://www.cmar.csiro.au/e-print/open/ gordon_2002a.pdf, 2002.

Gordon, H. B., O'Farrell, S. P., Collier, M. A., Dix, M. R., Rotstayn, L. D., Kowalczyk, E. A., Hirst, A. C., and Watterson, I. G.: The CSIRO Mk3.5 Climate Model, Technical Report No. 21, The Centre for Australian Weather and Climate Research, Aspendale, Vic., Australia, 62 pp., available online at: http://www.cawcr.gov. au/publications/technicalreports.php, 2010.

Han, W., Meehl, G. A., Rajagopalan, B., Fasullo, J. T., Hu, A., Lin, J., Large, W. G., Wang, J.-W., Quan, X.-W., Trenary, L. L., Wallcraft, A., Shinoda, T., and Yeager, S.: Patterns of Indian Ocean sea-level change in a warming climate, Nature Geosci., 3, 546550, doi:10.1038/ngeo901, 2010.

Hansen, J. and Nazarenko, L.: Soot climate forcing via snow and ice albedos, P. Natl. Acad. Sci., 101, 423-428, doi:10.1073/pnas.2237157100, 2004.

Hansen, J., Sato, M., Nazarenko, L., Ruedy, R., Lacis, A., Koch, D., Tegen, I., Hall, T., Shindell, D., Santer, B., Stone, P., Novakov, T., Thomason, L., Wang, R., Wang, Y., Jacob, D., Hollandsworth, S., Bishop, L., Logan, J., Thompson, A., Stolarski, R., Lean, J., Willson, R., Levitus, S., Antonov, J., Rayner, N., Parker, D., and Christy, J.: Climate forcings in Goddard Institute for Space Studies SI2000 simulations, J. Geophys. Res., 107, 4737, doi:10.1029/2001JD001143, 2002.

Hastenrath, S. and Polzin, D.: Dynamics of the surface wind field over the equatorial Indian Ocean, Q. J. Roy. Meteorol. Soc., 130, 503-517, doi:10.1256/qj.03.79, 2004.

Held, I. M. and Soden, B. J.: Robust Responses of the Hydrological Cycle to Global Warming, J. Climate, 19, 5686-5699, doi:10.1175/JCLI3990.1, 2006.

Hendon, H. H.: Indonesian rainfall variability: Impacts of ENSO and local air-sea interaction, J. Climate, 16, 1775-1790, 2003.

Hendon, H. H., Lim, E. P., and Liu, G.: The role of air-sea interaction for prediction of Australian summer monsoon rainfall, J. Climate, 25, 1278-1290, doi:10.1175/JCLI-D-11-00125.1, 2012. 
Hirst, A. C. and Godfrey, J. S.: The role of Indonesian throughflow in a global ocean GCM, J. Phys. Oceanogr., 23, 1057-1086, doi:10.1175/1520-0485(1993)023;1057:TROITI $\dot{i} 2.0$. CO;2, 1993.

Jones, D. A., Wang, W., and Fawcett, R.: High-quality spatial climate data-sets for Australia, Aust. Meteorol. Oceanogr. J., 58, 233-248, 2009.

Kajikawa, Y., Wang, B., and Yang, J.: A multi-time scale Australian monsoon index, Int. J. Climatol., 30, 1114-1120, doi:10.1002/joc.1955, 2010.

Kalnay, E., Kanamitsu, M., Kistler, R., Collins, W., Deaven, D., Gandin, L., Iredell, M., Saha, S., White, G., Woollen, J., Zhu, Y., Chelliah, M., Ebisuzaki, W., Higgins, W., Janowiak, J., Mo, K. C., Ropelewski, C., Wang, J., Leetmaa, A., Reynolds, R., Jenne, R., and Joseph, D.: The NCEP/NCAR 40-year reanalysis project, B. Am. Meteorol. Soc., 77, 437-471, 1996.

Kanamitsu, M., Ebisuzaki, W., Woollen, J., Yang, S. K., Hnilo, J. J., Fiorino, M., and Potter, G. L.: NCEP-DOE AMIPII reanalysis (R-2), B. Am. Meteorol. Soc., 83, 1631-1643, doi:10.1175/BAMS-83-11-1631, 2002.

Kang, S. M., Polvani, L. M., Fyfe, J. C., and Sigmond, M.: Impact of polar ozone depletion on subtropical precipitation, Science, 332, 951-954, doi:10.1126/science.1202131, 2011.

Kawase, H., Abe, M., Yamada, Y., Takemura, T., Yokohata, T., and Nozawa, T.: Physical mechanism of long-term drying trend over tropical North Africa, Geophys. Res. Lett., 37, L09706, doi:10.1029/2010GL043038, 2010.

Klein, S. A., Soden, B. J., and Lau, N. C.: Remote sea surface temperature variations during ENSO: Evidence for a tropical atmospheric bridge, J. Climate, 12, 917-932, 1999.

Kloster, S., Dentener, F., Feichter, J., Raes, F., Lohmann, U., Roeckner, E., and Fischer-Bruns, I.: A GCM study of future climate response to aerosol pollution reductions, Climate Dyn., 34, 11771194, doi:10.1007/s00382-009-0573-0, 2010.

Knutson, T. R. and Manabe, S.: Time-Mean Response over the Tropical Pacific to Increased $\mathrm{CO}_{2}$ in a Coupled OceanAtmosphere Model, J. Climate, 8, 2181-2199, 1995.

Kristjánsson, J. E., Iversen, T., Kirkevåg, A., Seland, Ø., and Debernard, J.: Response of the climate system to aerosol direct and indirect forcing: Role of cloud feedbacks, J. Geophys. Res., 110, D24206, doi:10.1029/2005JD006299, 2005.

Lamarque, J.-F., Bond, T. C., Eyring, V., Granier, C., Heil, A., Klimont, Z., Lee, D., Liousse, C., Mieville, A., Owen, B., Schultz, M. G., Shindell, D., Smith, S. J., Stehfest, E., Van Aardenne, J., Cooper, O. R., Kainuma, M., Mahowald, N., McConnell, J. R., Naik, V., Riahi, K., and van Vuuren, D. P.: Historical (1850-2000) gridded anthropogenic and biomass burning emissions of reactive gases and aerosols: methodology and application, Atmos. Chem. Phys., 10, 7017-7039, doi:10.5194/acp10-7017-2010, 2010.

Latif, M., Sperber, K., Arblaster, J., Braconnot, P., Chen, D., Colman, A., Cubasch, U., Cooper, C., Delecluse, P., Dewitt, D., Fairhead, L., Flato, G., Hogan, T., Ji, M., Kimoto, M., Kitoh, A., Knutson, T., Le Treut, H., Li, T., Manabe, S., Marti, O., Mechoso, C., Meehl, G., Power, S., Roeckner, E., Sirven, J., Terray, L., Vintzileos, A., Voß, R., Wang, B., Washington, W., Yoshikawa, I., Yu, J., and Zebiak, S.: ENSIP: the El Niño simulation intercomparison project, Climate Dyn., 18, 255-276, doi:10.1007/s003820100174, 2001.
Lau, N. C. and Nath, M. J.: Impact of ENSO on the variability of the Asian-Australian monsoons as simulated in GCM experiments, J. Climate, 13, 4287-4309, doi:10.1175/15200442(2000)013<4287:IOEOTV>2.0.CO;2, 2000.

Lean, J.: Evolution of the Sun's spectral irradiance since the Maunder Minimum, Geophys. Res. Lett., 27, 2425-2428, doi:10.1029/2000GL000043, 2000 .

Liepert, B. G., Feichter, J., Lohmann, U., and Roeckner, E.: Can aerosols spin down the water cycle in a warmer and moister world?, Geophys. Res. Lett., 31, L06207, doi:10.1029/2003GL019060, 2004.

Lin, J.-L.: The double-ITCZ problem in IPCC AR4 coupled GCMs: Ocean-atmosphere feedback analysis, J. Climate, 20, 44974525, doi:10.1175/JCLI4272.1, 2007.

Lin, Z. and Li, Y.: Remote influence of the tropical Atlantic on the variability and trend in North West Australia summer rainfall, J. Climate, 25, 2408-2420, 2012.

Lindzen, R. S. and Nigam, S.: On the Role of Sea Surface Temperature Gradients in Forcing Low-Level Winds and Convergence in the Tropics., J. Atmos. Sci., 44, 2418-2436, doi:10.1175/15200469(1987)044<2418:OTROSS > 2.0.CO;2, 1987.

Liu, Z., Vavrus, S., He, F., Wen, N., and Zhong, Y.: Rethinking Tropical Ocean Response to Global Warming: The Enhanced Equatorial Warming, J. Climate, 18, 4684-4700, doi:10.1175/JCLI3579.1, 2005.

Lohmann, U., Rotstayn, L., Storelvmo, T., Jones, A., Menon, S., Quaas, J., Ekman, A. M. L., Koch, D., and Ruedy, R.: Total aerosol effect: radiative forcing or radiative flux perturbation?, Atmos. Chem. Phys., 10, 3235-3246, doi:10.5194/acp-10-32352010, 2010.

Lu, J., Chen, G., and Frierson, D. M. W.: Response of the Zonal Mean Atmospheric Circulation to El Nino versus Global Warming, J. Climate, 21, 5835-5851, doi:10.1175/2008JCLI2200.1, 2008.

Luffman, J. J., Taschetto, A. S., and England, M. H.: Global and Regional Climate Response to Late Twentieth-Century Warming over the Indian Ocean, J. Climate, 23, 1660-1674, doi:10.1175/2009JCLI3086.1, 2010.

Matsuno, T.: Quasi-geostrophic motions in the equatorial area, J. Meteorol. Soc. Japan, 44, 25-43, 1966.

Meehl, G. A., Stocker, T. F., Collins, W. D., Friedlingstein, P., Gaye, A. T., Gregory, J. M., Kitoh, A., Knutti, R., Murphy, J. M., Noda, A., Raper, S. C. B., Watterson, I., Weaver, A. J., and Zhao, Z.-C.: Global Change Projections, in: Climate Change 2007: The Physical Science Basis. Contribution of Working Group I to the Fourth Assessment Report of the Intergovernmental Panel on Climate Change, edited by: Solomon, S., Qin, D., Manning, M., Chen, Z., Marquis, M., Averyt, K. B., Tignor, M., and Miller, H. L., Cambridge University Press, Cambridge, United Kingdom and New York, NY, USA, 2007.

Meehl, G. A., Arblaster, J. M., and Collins, W. D.: Effects of Black Carbon Aerosols on the Indian Monsoon, J. Climate, 21, 2869 2882, doi:10.1175/2007JCLI1777.1, 2008.

Meng, Q., Latif, M., Park, W., Keenlyside, N. S., Semenov, V. A., and Martin, T.: Twentieth century Walker Circulation change: data analysis and model experiments, Climate Dyn., 38, 1-17, doi:10.1007/s00382-011-1047-8, 2012.

Meyers, G.: Variation of Indonesian Throughflow and the El Niño-Southern Oscillation, J. Geophys. Res., 101, 12255-12264, 
doi:10.1029/95JC03729, 1996.

Ming, Y. and Ramaswamy, V.: Nonlinear climate and hydrological responses to aerosol effects, J. Climate, 22, 1329-1339, doi:10.1175/2008JCLI2362.1, 2009.

Ming, Y. and Ramaswamy, V.: A model investigation of aerosolinduced changes in tropical circulation, J. Climate, 24, 51255133, doi:10.1175/2011JCLI4108.1, 2011.

Ming, Y., Ramaswamy, V., and Persad, G.: Two opposing effects of absorbing aerosols on global-mean precipitation, Geophys. Res. Lett., 37, L13701, doi:10.1029/2010GL042895, 2010.

Moss, R. H., Edmonds, J. A., Hibbard, K. A., Manning, M. R., Rose, S. K., van Vuuren, D. P., Carter, T. R., Emori, S., Kainuma, M., Kram, T., Meehl, G. A., Mitchell, J. F. B., Nakicenovic, N., Riahi, K., Smith, S. J., Stouffer, R. J., Thomson, A. M., Weyant, J. P., and Wilbanks, T. J.: The next generation of scenarios for climate change research and assessment, Nature, 463, 747-756, doi:10.1038/nature08823, 2010.

Moura, A. D. and Shukla, J.: On the Dynamics of Droughts in Northeast Brazil: Observations, Theory and Numerical Experiments with a General Circulation Model., J. Atmos. Sci., 38, 2653-2675, doi:10.1175/15200469(1981)038<2653:OTDODI > 2.0.CO;2, 1981.

Parker, D., Folland, C., Scaife, A., Knight, J., Colman, A., Baines, P., and Dong, B.: Decadal to multidecadal variability and the climate change background, J. Geophys. Res., 112, D18115, doi:10.1029/2007JD008411, 2007.

Power, S., Casey, T., Folland, C., Colman, A., and Mehta, V.: Interdecadal modulation of the impact of ENSO on Australia, Climate Dyn., 15, 319-324, doi:10.1007/s003820050284, 1999.

Power, S. B. and Kociuba, G.: What caused the observed TwentiethCentury weakening of the Walker circulation?, J. Climate, 24, 6501-6514, doi:10.1175/2011JCLI4101.1, 2011.

Ramanathan, V., Chung, C., Kim, D., Bettge, T., Buja, L., Kiehl, J. T., Washington, W. M., Fu, Q., Sikka, D. R., and Wild, M.: Atmospheric Brown Clouds: Impacts on South Asian Climate and Hydrological Cycle, P. Natl. Acad. Sci., 102, 5326-5333, 2005.

Rao, S. A. and Yamagata, T.: Abrupt termination of Indian Ocean dipole events in response to intraseasonal disturbances, Geophys. Res. Lett., 31, L19306, doi:10.1029/2004GL020842, 2004.

Rayner, N. A., Parker, D. E., Horton, E. B., Folland, C. K., Alexander, L. V., Rowell, D. P., Kent, E. C., and Kaplan, A.: Globally complete analyses of sea surface temperature, sea ice and night marine air temperature, J. Geophys. Res., 108, 4407, doi:10.1029/2002JD002670, 2003.

Roberts, D. L. and Jones, A.: Climate sensitivity to black carbon aerosol from fossil fuel combustion, J. Geophys. Res., 109, D16202, doi:10.1029/2004JD004676, 2004.

Rodwell, M. J. and Hoskins, B. J.: Subtropical anticyclones and summer monsoons, J. Climate, 14, 3192-3211, doi:10.1175/1520-0442(2001)014<3192:SAASM>2.0.CO;2, 2001.

Roeckner, E., Stier, P., Feichter, J., Kloster, S., Esch, M., and Fischer-Bruns, I.: Impact of carbonaceous aerosol emissions on regional climate change, Clim. Dyn., 27, 553-571, doi:10.1007/s00382-006-0147-3, 2006.

Rotstayn, L. D. and Lohmann, U.: Tropical Rainfall Trends and the Indirect Aerosol Effect, J. Climate, 15, 2103-2116, doi:10.1175/1520-0442(2002)015<2103:TRTATI > 2.0.CO;2,
2002.

Rotstayn, L. D. and Penner, J. E.: Indirect aerosol forcing, quasi-forcing and climate response, J. Climate, 14, 2960-2975, doi:10.1175/1520-0442(2001)014<2960:IAFQFA>2.0.CO;2, 2001.

Rotstayn, L. D., Ryan, B. F., and Penner, J. E.: Precipitation changes in a GCM resulting from the indirect effects of anthropogenic aerosols, Geophys. Res. Lett., 27, 3045-3048, doi:10.1029/2000GL011737, 2000.

Rotstayn, L. D., Cai, W., Dix, M. R., Farquhar, G. D., Feng, Y., Ginoux, P., Herzog, M., Ito, A., Penner, J. E., Roderick, M. L., and Wang, M.: Have Australian Rainfall and Cloudiness Increased Due to the Remote Effects of Asian Anthropogenic Aerosols?, J. Geophys. Res., 112, D09202, doi:10.1029/2006JD007712, 2007.

Rotstayn, L. D., Collier, M. A., Feng, Y., Gordon, H. B., O’Farrell, S. P., Smith, I. N., and Syktus, J.: Improved simulation of Australian climate and ENSO-related rainfall variability in a GCM with an interactive aerosol treatment, Int. J. Climatol., 30, 10671088, doi:10.1002/joc.1952, 2010.

Saji, N. H., Goswami, B. N., Vinayachandran, P. N., and Yamagata, T.: A dipole mode in the tropical Indian Ocean, Nature, 401, 360363, 1999.

Sato, M., Hansen, J. E., McCormick, M. P., and Pollack, J. B.: Stratospheric aerosol optical depth, 1850-1990, J. Geophys. Res., 98, 22987-22994, 1993.

Schneider, N.: The Indonesian Throughflow and the global climate system., J. Climate, 11, 676-689, doi:10.1175/15200442(1998)011<0676:TITATG > 2.0.CO;2, 1998.

Schott, F. A., Xie, S.-P., and McCreary, J. P.: Indian Ocean circulation and climate variability, Rev. Geophys., 47, RG1002, doi:10.1029/2007RG000245, 2009.

Schulz, M., Textor, C., Kinne, S., Balkanski, Y., Bauer, S., Berntsen, T., Berglen, T., Boucher, O., Dentener, F., Guibert, S., Isaksen, I. S. A., Iversen, T., Koch, D., Kirkevåg, A., Liu, X., Montanaro, V., Myhre, G., Penner, J. E., Pitari, G., Reddy, S., Seland, $\varnothing$., Stier, P., and Takemura, T.: Radiative forcing by aerosols as derived from the AeroCom present-day and pre-industrial simulations, Atmos. Chem. Phys., 6, 5225-5246, doi:10.5194/acp-65225-2006, 2006.

Shi, G., Cai, W., Cowan, T., Ribbe, J., Rotstayn, L., and Dix, M.: Variability and trend of north west Australia rainfall: observations and coupled climate modeling, J. Climate, 21, 2938-2959, doi:10.1175/2007JCLI1908.1, 2008.

Shine, K. P., Cook, J., Highwood, E. J., and Joshi, M. M.: An alternative to radiative forcing for estimating the relative importance of climate change mechanisms, Geophys. Res. Lett., 30, 2047, doi:10.1029/2003GL018141, 2003.

Smith, T. M., Reynolds, R. W., Peterson, T. C., and Lawrimore, J.: Improvements to NOAA's historical merged land-ocean surface temperature analysis (1880-2006), J. Climate, 21, 2283-2296, doi:10.1175/2007JCLI2100.1, 2008.

Taschetto, A. S., Sen Gupta, A., Hendon, H. H., Ummenhofer, C. C., and England, M. H.: The Contribution of Indian Ocean Sea Surface Temperature Anomalies on Australian Summer Rainfall during El Nino Events, J. Climate, 24, 3734-3747, doi:10.1175/2011JCLI3885.1, 2011.

Taylor, K. E., Stouffer, R. J., and Meehl, G. A.: A Summary of the CMIP5 Experiment Design, http://cmip-pcmdi.llnl.gov/cmip5/ docs/Taylor_CMIP5_design.pdf, 2009. 
Taylor, K. E., Stouffer, R. J., and Meehl, G. A.: An Overview of CMIP5 and the Experiment Design, B. Am. Meteorol. Soc., 93, 485-498, 2012.

Tokinaga, H., Xie, S.-P., Timmermann, A., McGregor, S., Ogata, T., Kubota, H., and Okumura, Y. M.: Regional patterns of tropical Indo-Pacific climate change: Evidence of the Walker Circulation weakening, J. Climate, 25, 1689-1710, 2012.

Trenary, L. L. and Han, W.: Causes of decadal subsurface cooling in the tropical Indian Ocean during 1961-2000, Geophys. Res. Lett., 35, L17602, doi:10.1029/2008GL034687, 2008.

Vecchi, G. A. and Soden, B. J.: Global Warming and the Weakening of the Tropical Circulation, J. Climate, 20, 4316-4340, doi:10.1175/JCLI4258.1, 2007.

Vecchi, G. A., Soden, B. J., Wittenberg, A. T., Held, I. M., Leetmaa, A., and Harrison, M. J.: Weakening of tropical Pacific atmospheric circulation due to anthropogenic forcing, Nature, 441, 73-76, doi:10.1038/nature04744, 2006.

Wang, B., Wu, R., and Fu, X.: Pacific-East Asian Teleconnection: How Does ENSO Affect East Asian Climate?, J. Climate, 13, 1517-1536, doi:10.1175/15200442(2000)013<1517:PEATHD>2.0.CO;2, 2000.

Wang, B., Wu, R. G., and Li, T.: Atmosphere-warm ocean interaction and its impacts on Asian-Australian monsoon variation, J. Climate, 16, 1195-1211, doi:10.1175/15200442(2003)16<1195:AOIAII>2.0.CO;2, 2003.

Wang, B., Lee, J.-Y., Kang, I. S., Shukla, J., Kug, J. S., Kumar, A., Schemm, J., Luo, J. J., Yamagata, T., and Park, C. K.: How accurately do coupled climate models predict the leading modes of Asian-Australian monsoon interannual variability?, Climate Dyn., 30, 605-619, doi:10.1007/s00382-007-0310-5, 2008.

Wang, Y.-M., Lean, J. L., and Sheeley, Jr., N. R.: Modeling the Sun's Magnetic Field and Irradiance since 1713, Astrophys. J., 625, 522-538, doi:10.1086/429689, 2005.

Wardle, R. and Smith, I. N.: Modeled response of the Australian monsoon to changes in land surface temperatures, Geophys. Res. Lett., 31, L16205, doi:10.1029/2004GL020157, 2004.

Watterson, I. G.: Relationships between southeastern Australian rainfall and sea surface temperatures examined using a climate model, J. Geophys. Res., 115, D10108, doi:10.1029/2009JD012120, 2010.
Watterson, I. G.: Understanding and partitioning future climates for Australian regions from CMIP3 using ocean warming indices, Climatic Change, 111, 903-922, 2012.

Wentz, F. J., Ricciardulli, L., Hilburn, K., and Mears, C.: How Much More Rain Will Global Warming Bring?, Science, 317, 233-235, doi:10.1126/science.1140746, 2007.

Williams, K. D., Jones, A., Roberts, D. L., Senior, C. A., and Woodage, M. J.: The response of the climate system to the indirect effects of anthropogenic sulfate aerosol, Climate Dyn., 17, 845-856, 2001.

Woodruff, S. D., Worley, S. J., Lubker, S. J., Ji, Z., Freeman, J. E., Berry, D. I., Brohan, P., Kent, E. C., Reynolds, R. W., Smith, S. R., and Wilkinson, C.: ICOADS Release 2.5: extensions and enhancements to the surface marine meteorological archive, Int. J. Climatol., 31, 951-967, doi:10.1002/joc.2103, 2011.

Wu, R. G., Kinter, J. L., and Kirtman, B. P.: Discrepancy of interdecadal changes in the Asian region among the NCEP-NCAR reanalysis, objective analyses, and observations, J. Climate, 18, 3048-3067, doi:10.1175/JCLI3465.1, 2005.

Xie, S.-P., Deser, C., Vecchi, G. A., Ma, J., Teng, H., and Wittenberg, A. T.: Global Warming Pattern Formation: Sea Surface Temperature and Rainfall, J. Climate, 23, 966-986, doi:10.1175/2009JCLI3329.1, 2010.

Zar, J. H.: Biostatistical Analysis, 3rd Edition, Prentice Hall International, London, 929 pp., 1996.

Zhang, C. and Zhang, H.: Potential impacts of East Asian winter monsoon on climate variability and predictability in the Australian summer monsoon region, Theor. Appl. Climatol., 101, 161-177, doi:10.1007/s00704-009-0246-2, 2010.

Zhang, H.: Diagnosing Australia-Asian monsoon onset/retreat using large-scale wind and moisture indices, Climate Dyn., 35, 601-618, doi:10.1007/s00382-009-0620-x, 2010.

Zhang, M. and Song, H.: Evidence of deceleration of atmospheric vertical overturning circulation over the tropical Pacific, Geophys. Res. Lett., 331, L12701, doi:10.1029/2006GL025942, 2006. 